OPEN ACCESS

Edited by:

Regis Kopper,

University of North Carolina at Greensboro, United States

Reviewed by:

Florian Daiber,

German Research Centre for Artificial

Intelligence, Germany

Harry Farmer,

University of Greenwich,

United Kingdom

*Correspondence:

Arthur Maneuvrie

arthur.maneuvrier@protonmail.com

Specialty section:

This article was submitted to Virtual Reality and Human Behaviour,

a section of the journal

Frontiers in Virtual Reality

Received: 11 June 2020 Accepted: 20 August 2020 Published: 29 October 2020

Citation: Maneuvrier A, Decker LM, Ceyte H,

Fleury $P$ and Renaud $P$ (2020) Presence Promotes Performance on a Virtual Spatial Cognition Task: Impact of Human Factors on Virtual Reality Assessment.

Front. Virtual Real. 1:571713. doi: 10.3389/frvir.2020.571713

\section{Presence Promotes Performance on a Virtual Spatial Cognition Task: Impact of Human Factors on Virtual Reality Assessment}

\author{
Arthur Maneuvrier ${ }^{1 *}$, Leslie Marion Decker ${ }^{2}$, Hadrien Ceyte ${ }^{3}$, Philippe Fleury ${ }^{1}$ and \\ Patrice Renaud ${ }^{4}$ \\ ${ }^{1}$ Erlis, Normandie Univ, UNICAEN, Caen, France, ${ }^{2}$ INSERM, COMETE, GIP CYCERON, Normandie Univ, UNICAEN, Caen, \\ France, ${ }^{3}$ DevAH, Université de Lorraine, Nancy, France, ${ }^{4}$ Laboratoire de Cyberpsychologie, Département de Psychologie, \\ Université du Québec en Outaouais, Gatineau, QC, Canada
}

The use of virtual reality in spatial cognition evaluation has been growing rapidly, mainly because of its potential applications in the training and diagnosis of cognitive impairment and its ability to blend experimental control and ecological validity. However, there are still many gray areas on virtual reality, notably on the sense of presence and its complex relationship to task performance. Performance in VR is often suggested to be influenced by other human factors including, amongst others, cybersickness, gender, video game experience, and field dependence. Would an individual experiencing more presence systematically show better performance? This study aimed to be part of a framework of virtual reality as this question is fundamental for rigorous assessment and diagnostics, and particularly in the spatial cognition field. Forty-eight healthy young subjects were recruited to take part in a virtual spatial cognition evaluation. Spatial cognition performance, along with their level of presence, cybersickness, video game experience, gender and field dependence, were measured. Matrix correlations were used, along with linear regressions and mediation analysis. Results show that presence promoted performance on the spatial cognition evaluation, while cybersickness symptoms hindered it, notably among women. The presence-performance relationship was not mediated by other human factors. Video game experience significantly predicted both sense of presence and cybersickness, the latter two being negatively correlated. Even if women experienced more negative symptoms than men, gender appears less informative than cybersickness and video game experience. Field dependence was not associated with any other variable. Results are discussed by confronting two theories of cognition (representational vs. ecological), highlighting that virtual reality is not a simple transposition of reality but truly a new paradigm with its own biases favoring some individuals more than others, and that some human factors have to be controlled for rigorous uses of virtual environments, particularly for spatial cognition evaluation.

Keywords: immersion, sense of presence, cybersickness, virtual environment (VE), human-computer interaction (HCI), head-mounted display (HMD), field dependence, spatial orientation and navigation 


\section{INTRODUCTION}

The tool of virtual reality (VR) is experiencing a new golden age, thanks in particular to the drop in cost in the years 2010 (Castelvecchi, 2016; Slater, 2018) and the possibility for developers to use free content (Cipresso et al., 2016, 2018). It is now recognized as a powerful tool of investigation, therapy and training in psychology, biomedical sciences, neurosciences and cognitive sciences (Gregg and Tarrier, 2007; Foreman, 2010; Bohil et al., 2011; Scozzari and Gamberini, 2011; Parsons et al., 2017; Cipresso et al., 2018; Pan and Hamilton, 2018; Clay et al., 2020). This appeal relies mostly on the possibility of maintaining ecological validity while retaining experimental control: VR is a technology that combines the best of both worlds (Minderer et al., 2016). It allows scientists to build an environment in which every sensorial stimulus can be customized and integrated into an ecological task while gathering data under highly controlled conditions (Parsons, 2015; Oliveira et al., 2017; Coleman et al., 2019).

VR and its ecological validity is particularly interesting in the spatial cognition field where pencil-and-paper tests show their limitations, notably when assessing large-scale navigation skills and strategies (Allahyar and Hunt, 2003; Cogné et al., 2017, 2018). Moreover, feasibility studies exist and strong correlations have already been found between real world and virtual navigational deficits (Cushman et al., 2008; Byagowi and Moussavi, 2012). The use of VR in spatial cognition has been growing rapidly, mainly because of its potential applications in the training and diagnosis of mild cognitive impairment (Allison et al., 2016; Cogné et al., 2017; Diersch and Wolbers, 2019; Ijaz et al., 2019; Kim et al., 2019; Zhou et al., 2020). This makes VR an interesting and promising tool to study, assess and train spatial cognition.

This beneficial asset is made possible by what is called the sense of presence. The sense of presence is now a famous human factor in VR: it is at the same time an easy to perceive phenomenological property, the sense "of being there" in the virtual environment (Heeter, 1992; Sheridan, 1992), and a complex to define theoretical concept. Most authors agree that the sense of presence is the subjective and dynamic consequence of immersion, which in turn refers to the technical characteristics of the system and the quantifiable description of technology (Slater and Wilbur, 1997). The sense of being located in another place than the one where we physically stand is sometimes called spatial presence or environment presence, to distinguish it from other subsets of presence as social presence or selfpresence (Heeter, 1992; Wirth et al., 2007). However, some authors will emphasize the media side and define it as the "illusion of non-mediation" (Lombard and Ditton, 1997), while others will emphasize on the inner side, the psychological and phenomenological aspect, sometimes suggested as strongly related to consciousness (Riva and Waterworth, 2003; Coelho et al., 2009). It is not the purpose of this study to propose the ultimate definition of presence, what is certain is that it is now considered by most researchers as a central part of VR and is, directly or indirectly at the heart of most in virtuo studies.
The present study aims to be part of the emergence of a body of knowledge and a methodological framework of VR (North and North, 2016). Indeed, there are still many gray areas around VR, notably on the sense of presence and its complex relationship to task performance, probably influenced by other human factors. Would an individual experiencing more presence systematically show better task performance in VR? How can we make rigorous VR assessment and diagnosis, for example of spatial cognition skills or deficits, if we do not know how the sense of presence and task performance are intertwined? These questions were raised at the very early stages of VR usage and still have no clear answer: "Not only is it necessary to develop a theory of presence for virtual environments, it is also necessary to develop a basic research program to investigate the relationship between presence and performance using virtual environments. [...] we need to determine when, and under what conditions, presence can be a benefit or a detriment to performance. [...] When simulation and virtual environments are employed, what is contributed by the sense of presence per se?" (Barfield et al., 1995). These studies are mandatory for a methodologically rigorous use of VR, either for research, diagnosis or rehabilitation purposes. In this context, we propose to investigate this relationship in the field of spatial cognition.

The usual global heuristic idea and usual experimental hypothesis on the relationship between presence and virtual performance is one of a positive correlation (Sheridan, 1992), even if some authors argue that a positive association is an exception and not the rule (Welch, 1999). It seems a priori natural to think that the more present in the virtual environment the individual is, the better he or she will perform. Indeed, attentional resources are often considered central to the concept of performance (Navon and Gopher, 1979) and presence: "The more attentional resources that a user devotes to stimuli presented by the displays, the greater the identification with the computermediated environment and the stronger the sense of telepresence" (Bystrom et al., 1999). But other works have outlined that the relationship between sense of presence, attentional resources and task performance is probably not that simple: attentional resources allocated to virtual stimuli unrelated to the task might enhance the sense of presence but decrease task performance (Draper and Blair, 1996; Draper et al., 1998). This issue is further complicated by the very different shapes that task performance can take, and the very different factors that may affect both performance and sense of presence. User interface, ergonomics and to some extent affordances (Grabarczyk and Pokropski, 2016) are at the heart of this question: "The affordances of the environment are what it offers the animal, what it provides or furnishes, either for good or ill. [... IIt implies the complementarity of the animal and the environment" (Gibson, 1979).

To understand this better, here is an adaptation of the analogy of Slater et al. (1996): let us imagine that participants are asked to perform a cognitive-motor test with balls thrown at them that they have to catch in a virtual environment, either with a strong transmission delay between their physical movement and their avatar movement, or without a transmission delay. Participants' performance on this task will most likely be stronger in the nodelay condition, but is it wise to attribute this effect to the sense 
of presence per se? Even though the sense of presence shall be higher in the no-delay group because of a better match between the sensory cues and the internally-generated representations (Barfield and Hendrix, 1995; Welch et al., 1996), it seems more relevant to attribute the virtual performance changes to the practicality of the human-computer interaction. Even if the correlation between sense of presence and performance might be strong and significant, the law of parsimony urges us to consider subject-object ecological quality: sensory-motor integrated tasks are particularly difficult to perform with transmission delay, which might make the relationship between sense of presence and virtual performance mediated. Besides this tricky question, it has been noted that it is often complicated to find a causation direction: does the individual perform better because he feels more present or does he feel more present because he performs better (Nash et al., 2000)? Even when putting causation or direction aside, reviews and experimental studies do not allow us to assert anything on the relationship between presence and performance: associations are sometimes found, often weak (Witmer and Singer, 1994; Slater et al., 1996; Pausch et al., 1997; Stanney et al., 2002; Youngblut and Huie, 2003; Stevens and Kincaid, 2015; Cooper et al., 2018) and sometimes not found at all (Ma and Kaber, 2006; Pallamin and Bossard, 2016).

One factor is mandatory to explore when studying this question as it may affect both virtual performance and sense of presence: cybersickness. Cybersickness is defined as a set of symptoms, close to those of motion sickness and caused by exposure to VR (Rebenitsch and Owen, 2016). There are two main theories relative to the origins of motion sickness (and cybersickness). The most famous one is the sensory mismatch (or conflict) theory between different sensory systems (Reason and Brand, 1975): just as a person in the hold of a ship receives vestibular motion input but no visual motion input, a person in VR, for example when moving, usually receives visual motion input but no vestibular motion input. The second theory argues that the symptoms come from a postural instability which always precedes the negative effects (Stoffregen and Smart, 1998). Whatever the cause, these symptoms have long hindered VR development (Shafer et al., 2017). Recently, a meta-analysis has shown that presence and cybersickness are negatively correlated (Weech et al., 2019). This observation is particularly interesting since cybersickness is also often negatively correlated to task performance. Indeed, some studies have found that negative motion sickness symptoms are linked to decreased cognitive performance (Kennedy et al., 1993; Gresty et al., 2008; Gresty and Golding, 2009), and it is often suggested that when no correlation is found it is due to the cybersickness symptoms being too mild to impact task performance (Bos et al., 2005). Considering these outcomes, it becomes imperative to incorporate cybersickness in the analysis of the relationship between sense of presence and virtual performance. For example, in our previous fictive cognitive-motor experiment, participants in the condition with transmission delays would experience more negative symptoms due to the delay and sensory mismatch (Bos et al., 2008; Weech et al., 2019), symptoms which may also help in explaining the task performance. It is arguable that cybersickness, by making individuals self-aware of their symptoms, drives attentional resources away from the task, reducing performance, and from the virtual environment, reducing the sense of presence.

A factor that might deserve more attention in the VR field is the cognitive style, and more precisely the field dependence dimension (Witkin et al., 1962). Field dependence corresponds to the degree to which the individual's perception and cognition depends on information from the perceptual visual field. This one dimension concept (from field dependence to field independence) is particularly interesting since while assessing the analytical vs. holistic perceptual abilities, it was primarily used to assess the degree to which an individual depends on the visual cues rather than other cues, for example vestibular or proprioceptive (Pithers, 2002). Besides, field independent individuals are usually said to have better working memory abilities, notably by inhibiting non-pertinent information (Pithers, 2002; Evans et al., 2013). Considering the close relationship between multisensory integration, cybersickness, attentional resources and sense of presence, the field dependence dimension should be considered in the VR equation. However, only one study has investigated the relationship between field dependence and presence on a specific type of presence: objects presence. In this study, Hecht and Reiner (2007) have found that sense of objects presence is negatively correlated to field dependence, and they suggest that a similar result might be found on spatial presence. They argue that field dependent individuals, being more impacted by the perceptual fields, are also more impacted by flaws in the environment. On the other hand, field independent individuals should be able to fill the gap of the visual environment based on their internal representation. It can be added that field dependent individuals, who use dominantly visual cues are more impacted by perceptual mismatch (Kennedy, 1975 ) and are less able to inhibit irrelevant visual stimuli (for example the ones from the real world), and thus should experience less sense of presence.

Another factor that needs to be considered in this complex relationship is the video game experience. Indeed, if VR has not yet been really adopted by the public, video gaming is now a sociological fact and both share many codes and processes. According to the Entertainment Software Associatio (2019), 65\% of American adults play video games ( $46 \%$ of them are female and $54 \%$ are males), while people who play video games spend an average of 7 hours and 7 minutes each week doing so. This certainly impact various aspects of people's lives (Jones et al., 2014; Boyle et al., 2016). It is reasonable to postulate that gaming experience helps an individual adapt to a virtual world and interact with it: besides sharing many ergonomics aspects and cognitive schemes, playing video games could lead to a cybersickness habituation, as discussed by Howarth and Hodder (2008). Indeed, a negative correlation between gaming experience and reduced cybersickness effects is often found (Knight and Arns, 2006; De Leo et al., 2014; Rosa et al., 2016) even though it is not always reproduced (Ling et al., 2013). However, the relationship between sense of presence and video game experience is unclear: some studies reported no relationship (Alsina-Jurnet and Gutiérrez-Maldonado, 2010) while others did, sometimes arguing that practice may enhance the sense of presence (Gamito et al., 2010; Lachlan and Krcmar, 
2011; Rosa et al., 2016). In addition, it is arguable that gaming improves task performance, and this beyond the humancomputer interaction familiarity: various studies have found that video game experience improves cognitive performance on different tasks, notably virtual navigation (Richardson et al., 2011; Murias et al., 2016), visuo-spatial abilities (Green and Bavelier, 2006), visual acuity (Green and Bavelier, 2007) and other cognitive, sensory and motor tasks (Boot et al., 2011; Pallavicini et al., 2018). It has to be noted that playing video games also seems to reduce gender differences in spatial cognition (Feng et al., 2016). However, using the video game experience as a single unitary concept might be too unspecific. Indeed, video game is a broad term that encompasses many different genres, and these different genres represent not only very different environments of playing, but also very different perceptive, cognitive and motor processes. Besides the genres themselves, a distinction is often made between "casual gaming" and "intensive gaming." Casual games are "games that are often catered to non-gamers and involve simple rules that allow for game completion in reasonably short periods of time." In addition, casual games are usually crossplatform and do not require heavy computation (Kuittinen et al., 2007; Juul, 2010; Baniqued et al., 2013). Examples of casual games might be puzzle or matching games. On the other hand, intensive games usually require a PC or a gaming console, need a training time to be grasped and are challenging for the player (especially when confronting other players) to the point that they might induce stress. These games are usually very stimulating and require a strong hand-eyes coordination. They usually cannot be finished or fully mastered, and more than often present a professional E-sports scene. In addition, these kind of games are the ones usually associated with gaming disorders (Green and Bavelier, 2003; Bosser and Nakatsu, 2006; Kapalo et al., 2015; Rehbein et al., 2016; Saputra et al., 2017). Examples of intensive games might be real time strategy or first-person shooter games.

Finally, yet importantly, the gender factor has often been suggested as potentially affecting the sense of presence in VR: the explicit title "Is VR made for men only? Exploring gender differences in the sense of presence" (Felnhofer et al., 2012) says it all, making the investigation of the gender effect in VR invaluable to understanding the relationship between human factors and performance. Authors have attributed the effect of gender on the sense of presence as the result of differences in the abilities to suspend disbelief (Slater and Usoh, 1994; Felnhofer et al., 2012), in spatial abilities (Felnhofer et al., 2012), in personality factors as extraversion and submissiveness (Lombard and Ditton, 1997), or in computer experience (Waller et al., 1998). For instance, Gamito et al. (2008) attributed gender differences in VR almost exclusively to differences in gaming experience. These differences in gaming experience are hard to evaluate since women nowadays seem to play nearly as much as men (Entertainment software association, 2019). However, there are still large differences in the genre of games played. Indeed, a report on more than 270,000 gamers (Yee, 2017) show that around 69\% of arcade and matching games players are women, while they constitute only $7 \%$ of first-person shooter players. Based on the previous distinction, casual gaming is shown in this report as mostly feminine while intensive gaming is mostly masculine. This effect is a difficult to explain cultural fact, which might be related to motivational competitive goals or the fact that many intensive video games are made for men, incorporating a strong sexualization of women (Hoeft et al., 2008; Behm-Morawitz and Mastro, 2009; Breuer et al., 2015; Fox and Potocki, 2016; Rehbein et al., 2016; Kowert et al., 2017). Considering the very different processes and environment between different game genres, the kind of games played should be integrated into the equation for a better understanding not only of the video game factor, but also the gender factor. Indeed, the gender factor is further complicated because it also has an impact on cybersickness, with women experiencing more symptoms than men (Shafer et al., 2017). Of note it remains unclear if this effect is biological (sex effect) or cultural (gender effect): some neuroendocrine responses to motion sickness have been found, such as changes in the secretion rate of adrenocorticotropic hormone and vasopressin (Weech et al., 2019), or some association with hormonal changes during the menstrual cycle (Clemes and Howarth, 2005). Since motion sickness symptoms are often considered as evolutionary responses to the potential ingestion of toxins (Treisman, 1977), and just as heightened sense of smell and susceptibility to sickness has been suggested as evolutionary processes to protect a child (Profet, 1992; Cameron, 2014), it is arguable in these views that women being more susceptible to cybersickness share similar explanations. Optical differences could also be implicated, as women generally have wider fields of view than men, which might increase the flicker perception and thus negative symptoms (LaViola, 2000). A mix of both gender and sex effect is probably the most relevant answer, as revealed by potential differences in cognitive style. Indeed, differences in early stage of life development games could lead to more field dependence: for example, boys being more prone, or culturally induced, to play 3D building games (Levine et al., 2016), this could help spatial cognition and thus reduce their visual field dependence, which is itself correlated to motion sickness susceptibility (Kennedy, 1975). Other cultural explanations for gender differences in cybersickness susceptibility might be that men underreport their negative symptoms in order to not appear weak (Rebenitsch and Owen, 2016), or that different interpupillary distances between men and women are uncontrolled when using headmounted displays, making the helmet unfit for women's smaller heads. In their study Stanney et al. (2020) found similar levels of cybersickness between genders when controlling for the interpupillary distances. No matter the sources of gender differences, it is arguable that men and women do not respond equally to VR and that these differences could lead to differences in performance, particularly in spatial cognition where women show a history of poorer performance (Silverman and Eals, 1992; Parsons et al., 2004; Levine et al., 2016; Tarampi et al., 2016).

Therefore, the objective of the present study is to investigate the relationship between sense of presence and performance during a spatial cognition VR task. In order to do so, it is necessary to explore and discuss the effects and interweaving of major human factors in VR (i.e., cybersickness, video game experience, gender, field dependence) potentially impacting performance, presence, and their relationship. Our main hypothesis is that sense of presence promotes spatial cognition 
performance and that other mentioned human factors build the sense of presence. In order to test this second hypothesis in the most unbiased way possible, secondary hypotheses have been put forward concerning the relationships between the various variables of interest based on the literature (Table 1). The question of the impact that presence might have on performance is mandatory for a rigorous use of VR in the spatial cognition evaluation, and the current study aims to help understanding it. However, the interrogations, results and discussions could be extrapolated and applied to other fields and applications, as it could help with outlining a new methodological and conceptual model of human factors and VR performance.

\section{MATERIALS AND METHODS}

\section{Participants}

Forty-eight healthy young adults (24 women, $20,2 \pm 2,8$ years old; 24 men, 20,4 \pm 2 years old were locally recruited in first and second year of psychology at the university. Exclusion criteria included: (i) under 18 or over 35 years of age, (ii) current or past presence of neurological or psychiatric disorders, (iii) visual impairments that do not allow stereoscopic vision, (iv) motor impairments that do not allow the use of hand controllers. The local ethics committee validated the experiment (\#CEREP-19011-PD). All the participants signed an informed consent form prior to data collection, and the procedure of Helsinki (World Medical Association, 2013) was strictly applied. Even though they were informed that they could stop the experiment at any time, none of them chose to.

\section{Virtual Environment}

A virtual environment was built using the Unity 3D engine and the C\# programming language by the authors of the study for the HTC-Vive head mounted display $(1,080 \times 1,200$ pixels per eye, $90 \mathrm{~Hz}, 110$ degrees field of view), using the OpenVR and SteamVR API and SDK (Figure 1). The VR system ran on a computer using a NVIDIA ${ }^{\circledR}$ GTX-1080 graphic card, 16 Go of RAM and an Intel Core $5^{\circledR}$, which ensured a consistent frame rate (i.e., 70 frames per second). HTC-Vive hand controllers were also used: participants could move in the environment by teleportation (they could press a button to point a spot on the floor in a range of 4 meters then release the button to move to the spot) in order to prevent cybersickness (Clifton and Palmisano, 2019). They could also open doors by touching it with the virtual representation of the controller.

The test environment was big enough to give the participants a feeling of openness but was in reality a guided pathway with 10 intersections (Figure 2), where the participants had to choose between two directions by opening doors. "Right" doors could be opened while "wrong doors" could not. This was made to give participants a sense of freedom (and sense of presence) without the possibility of losing themselves in the environment. Every pathway had a unique visual cue (e.g., a statue, a fountain, a tree...). The environment included different small assets to increase the participant's sense of presence and help the smoothness of the procedure. First, interactive audio was included with footsteps or doors: opening a "good" door emitted a naturalistic sound, and so did trying to open a "wrong," closed door. Secondly, two ambient sounds (wind, birds) were looping in the background. Finally, some artificial intelligent birds were flying far above the environment, making birds sounds. All sounds, excluded ambient sounds, were 3D localized.

\section{Spatial Cognition Performance}

The spatial cognition performance was inspired by Cushman et al. (2008). After a first guided visit in the virtual environment ("Follow the signs on the way. There is no time limit, but try to be as fast as possible"), participants had to answer in the virtual environment to different items: photo recognition (fake and true photo of the environment were shown, they had to say if these images were or were not extracted from the visited virtual environment), pathway recognition (participants had to say if they had taken the left or right way on a pathway photo), photo position (participants had to put photos of the environment on a continuum from "start" to "end" of the visit), video position (participants had to put videos of the environment on a continuum from "start" to "end" of the visit). Participants were then virtually replaced to the beginning of the environment and had to start over, but the wooden signs were removed ("You now have to redo the visit, but without the signs to help you. There is no time limit but try to be as fast as possible"). Finally, an ultimate item was measured: free recall ("Enumerate, out loud, every environmental item that helped you find your way in the environment"). Two items from Cushman et al. (2008) were not integrated in this study: route drawing, where participants have to draw a scaled map of the route, and selflocation, where participants have to point in the direction of shown pictures. The choice was made not to integrate route drawing because of its arbitrary evaluation when the route is not exactly composed of straight segments, as it was the case in Cushman et al. (2008). In our experiment, the environment was not composed of segments but of "areas": participants had much more freedom until they met a choke point, which allowed for a better ecological dimension, but makes the evaluation of route drawing more problematic. Indeed, in order to propose a methodological evaluation, route drawing would have required a comparison with each individual's own route, which could possibly be automated in the future but was not done in this study. Self-location was not integrated because of the extreme difficulty and lack of results outlined by preliminary results. This extreme difficulty might come in VR from the possible mismatch between movement direction and body's position when using teleportation. Indeed, since participants move by pointing the controllers in their hand, they do not have to exactly face the direction they are going in, resulting in a complete lack of pertinence of the self-orientation sub-item and an induced demoralizing effect.

Recalling items were all scored continuously from 0 to 1 . The number of "wrong" doors that the participants tried to open during the second visit was scored from 0 (no wrong doors attempted) to 1 (all wrong doors attempted), with a score of 0.5 meaning that half of the wrong doors were tried. Navigational skills were scored as follows from 0 to 1 : (length time of the second visit)/(length time of the first visit + length time of the 
TABLE 1 | Summary of variables and hypotheses in this study.

\begin{tabular}{|c|c|c|c|c|c|}
\hline & $\begin{array}{c}\text { Spatial cognition } \\
\text { performance }\end{array}$ & $\begin{array}{l}\text { Sense of } \\
\text { presence }\end{array}$ & Cybersickness & $\begin{array}{l}\text { Video game } \\
\text { experience }\end{array}$ & $\begin{array}{c}\text { Visual field } \\
\text { dependence }\end{array}$ \\
\hline \multicolumn{6}{|l|}{$\begin{array}{l}\text { Spatial cognition } \\
\text { performance }\end{array}$} \\
\hline Sense of presence & + & & & & \\
\hline Cybersickness & - & - & & & \\
\hline Video game experience & + & + & - & & \\
\hline Visual field dependence & - & - & + & - & \\
\hline Feminine gender & - & - & + & - & + \\
\hline
\end{tabular}

A "+" means a hypothesis of positive correlation and a "-" means a hypothesis of negative correlation.
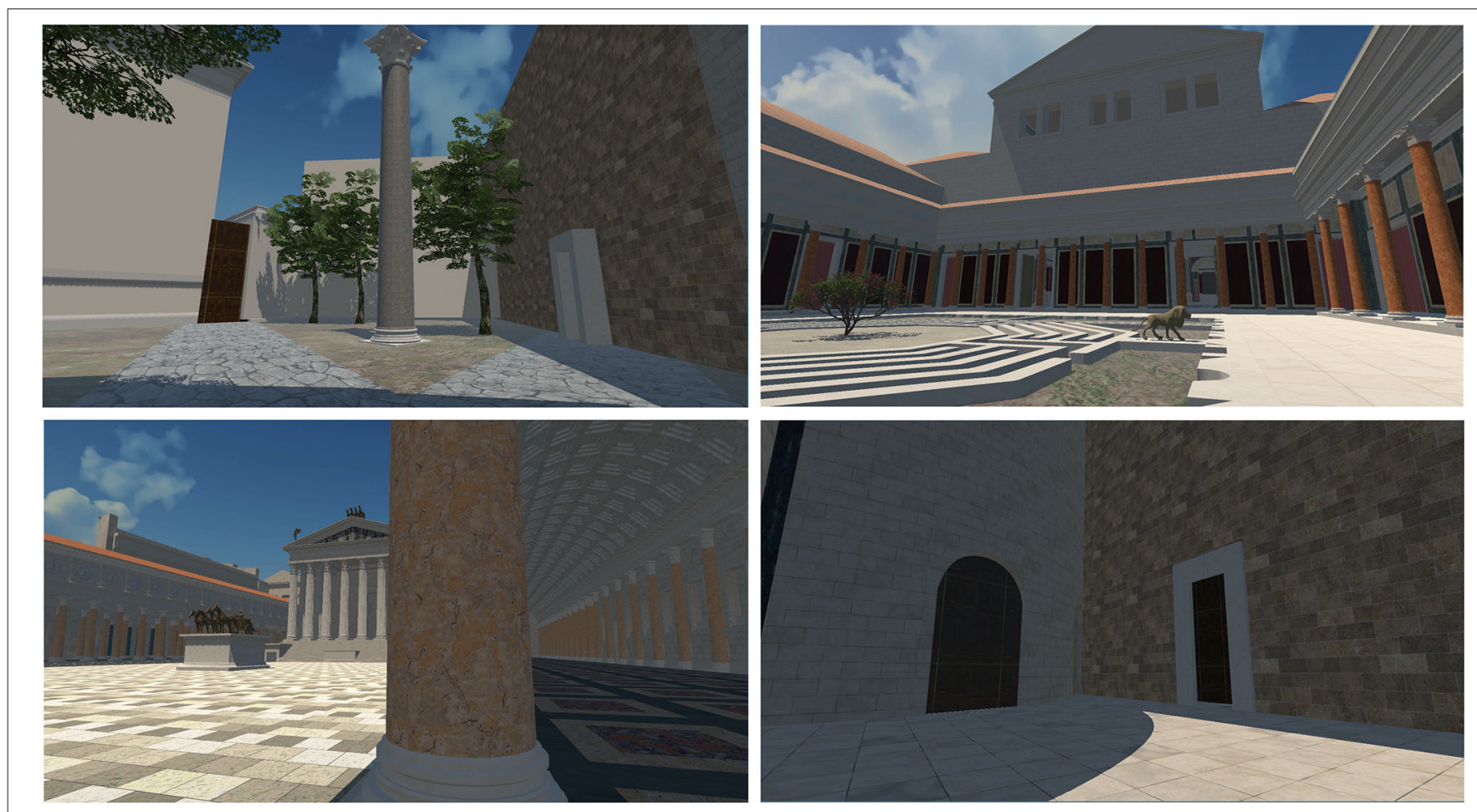

FIGURE 1 | Screenshots of the virtual environment from the perspective of the user. First and last pictures show two of the 10 intersections for which the participant had to choose between two different doors based on his/her first visit.

second visit). Incorporating the length time of the first visit allowed ergonomic factors to be controlled for and thus more precisely evaluated spatial navigation performance. Final spatial cognition performance score was obtained by summing every sub item. Errors were coded positively but reversed for clarity; a lower score indicates a lower performance.

\section{Experimental Procedure}

Prior spatial cognition evaluation the visual field dependence was evaluated using a Rod-and-Frame Test (RFT) in a virtual environment (RVR software by Virtualis ${ }^{\circledR}$ ). Positioned in an upright seated position and equipped with a VR headset, participants had to align, via a joystick, a rod initially tilted 27 degrees to earthly vertical (0 degree), in a fixed frame laterally tilted 18 degrees. Sixteen trials were performed from balanced order combinations of two right and left rod tilts and two right and left frame tilts. For each trial, the absolute error (in degree) relative to the earth vertical was recorded. The degree of visual dependence was quantified using the mean absolute error. The higher the mean absolute error, the more the subjective vertical is influenced by the tilted frame, and thus the more the subject is field dependent. Once the virtual spatial cognition test was completed, participants had to respond (auto-administration) to (i) the French adaptation of the Questionnaire of Presence, except the haptic items (Robillard et al., 2002), and (ii) to the French adaptation of the Simulator Sickness Questionnaire (Bouchard et al., 2007). The Presence Questionnaire was chosen because of two reasons. First, it is the most commonly used questionnaire (Schwind et al., 2019), which allows for inter-experimentations comparisons. Secondly, 


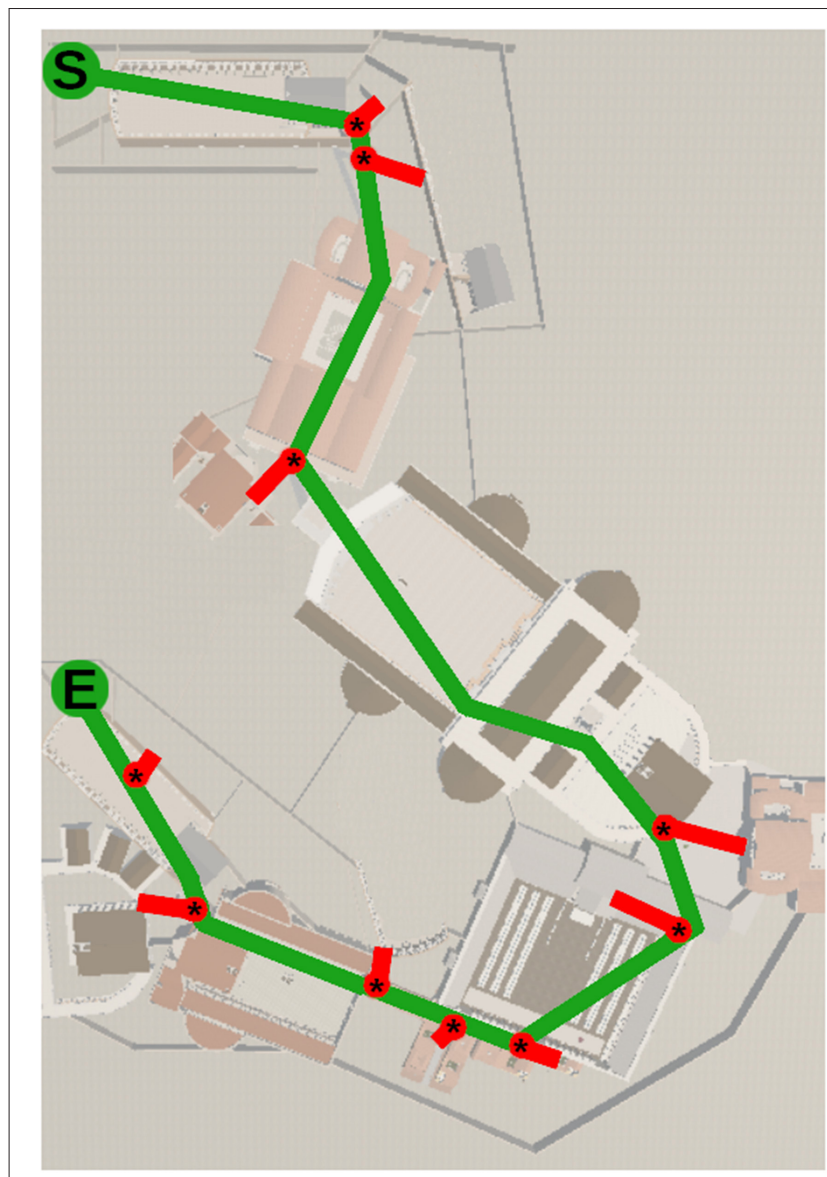

FIGURE 2 | Aerial view of the virtual environment. The green line represents the correct way, and red lines represent wrong ways which led to closed doors. Asterisks represent the location of choke points associated with visual cues, which were also the location of signs leading the participant in the learning phase. "S" represents the starting location and "E" the ending location.

contrary to other presence questionnaires like the SUS or the IGP (Slater et al., 1994; Schubert et al., 2001; Schwind et al., 2019), the Presence Questionnaire does not ask for the participants to directly rate their level of presence, which might prevent the bias of past facto construction as raised by Slater (2004). In addition, the game experience was gathered through the product of two items. First, a simple, single 7-point (Likert) item in order to determine the gaming frequency: "How often do you play video games?" From 1 (never) to 7 (everyday). Secondly, a multi-answer question in order to determine the genre of games played: "If you play video games, what kind of game do you usually play (check zero to three of the games genre you play the most): Real time strategy and multiplayer online battle arena/Simulation/Puzzle \& Arcade/First-Person Shooters/Platformers/Role-play and adventure." Each type was followed by a few examples in order to guide the participants: for example First-Person Shooters was followed by "Counter Strike, Overwatch, Apex Legends, Call of Duty, Fortnite ..." while Arcade and Puzzle was followed by "Candy Crush, Fruits
Ninja, Space Invader, Pac-Man, Overcooked! ...”. Participants reporting playing intensive games (Real time strategy and multiplayer online battle arena/First-Person Shooter/Role-play and adventure) were coded as " 2 " on the video game genre, and participants reporting playing no intensive games (Simulation/Puzzle \& Arcade/Platformers/No genre checked) were coded as "1." The whole video game experience variable was constituted on the product of the video game frequency and video game genre.

\section{Statistical Analysis}

All statistical analyses were performed using JASP version 0.2.12.1, unless specified. Descriptive statistics were performed on the spatial cognition scores, notably reliability's analysis based on the McDonald's Omega. One sample Student $t$-tests on the Presence Questionnaire and the Simulator Sickness Questionnaire were used in order to compare our experimental data with the reference data. Video game frequency, genres and experience were explored using descriptive statistics, McDonald's Omega and Pearson's correlation $r$ coefficient. Pearson's correlation coefficient was also used to explore the associations between the different variables of interest (i.e: spatial cognition performance, sense of presence, cybersickness, gender, video game experience, and visual field dependence). Because our a priori predictions were directional, one-tailed tests were used for correlations analyses. Enter linear regressions based on our theoretical hypotheses were then used to evaluate the potential predicting weight of each variable and their interaction on every VR related variables: spatial cognition performance, sense of presence and cybersickness. Because of the small sample size, sensitivity analyses were performed using $G^{*}$ Power version 3.1.97. To avoid redundancy, spatial cognition scores were not considered in the potential predictors of sense of presence, and sense of presence scores were not considered in the potential predictors of cybersickness. Finally, a mediation analysis on the relationship between sense of presence and performance, using the most significant retained variables as mediators, was performed. Multicollinearity was tested using variance inflation factors. The significance threshold was set at 0.05 and a trend toward significance was interpreted for a $p$ value between 0.05 and 0.1 . Size effects were reported through the $r$ coefficient for correlations, Cohen's $d$ for Student $t$-tests and the $f^{2}$ for linear regressions. Confidence intervals were set at $95 \%$ and systematically reported. One outlier was removed from the analyses.

\section{RESULTS}

\section{Preliminary Analyses Spatial Cognition Performance}

With a global mean of $2.433 \pm 0.49$ and a McDonald's $\omega$ of 0.7614 , we considered the different sub-items of the spatial cognition evaluation to show a relative reliability. As a result, we used the global measure (the sum of every item) independently and unitary. 


\section{Presence Questionnaire}

With a global mean (without haptics, audio and resolution items) of $100.1 \pm 10.38$ compared to the $91.96 \pm 18.99$ of the original data from the Questionnaire sur l'Etat de Présence, the $t$-test of Student for one sample revealed significant differences in the sense that our participants reported more presence: $t_{(46)}=5.39, p$ $=0.001$, Cohen's $d=0.786,95 \%$ CI $[0.455,1.111]$. This was also true for each sub-item of the questionnaire: realism $\left(t_{(46)}=4.387\right.$, $p=0.001$, Cohen's $d=0.598,95 \%$ CI $[0.284,0.906])$, possibility to act $\left(t_{(46)}=2.975, p=0.005\right.$, Cohen's $d=0.434,95 \%$ CI [0.132, $0.731])$, quality of interface $\left(t_{(46)}=3.54, p=0.001\right.$, Cohen's $d$ $=0.517,95 \%$ CI $[0.210,0.819])$, possibility to examine $\left(t_{(46)}=\right.$ $2.11, p=0.04$, Cohen's $d=0.309,95 \%$ CI $[0.014,0.6])$ and selfevaluation of performance $\left(t_{(46)}=3.97, p=0.001\right.$, Cohen's $d=$ $0.58,95 \%$ CI $[0.268,0.887])$.

\section{Cybersickness Questionnaire}

With a global raw scores mean of $5.3 \pm 3.67$ compared to the $7.12 \pm 6.04$ of the original data from the Questionnaire sur les Cybermalaises, the $t$-test of Student for one sample on raw scores revealed significant differences in the sense that our participants reported less cybersickness: $t_{(46)}=-3.4, p=0.001$, Cohen's $d=$ $-0.49,95 \%$ CI $[-0.796,-0.19]$.

\section{Video Game Experience}

The mean frequency of video game practice on a Likert scale from 1 (Never) to 7 (Every day) was $3.83 \pm 2.05$. Men reported a mean of $4.3 \pm 1.91$ and women a mean of $3.37 \pm 2.12$. Considering the genre of games played, 29 participants reported playing at least predominantly one or more intensive games (19 men, 10 women), while 18 reported playing only casual games ( 4 men, 14 women). No significant correlation between genders and video game frequency were found, but playing intensive games was significantly correlated with masculine gender $(r=0.421, p=$ 0.003 ) and video game frequency $(r=0.558, p=0.001)$. Video game genres (intensive, casual) and video game frequency taken together show a strong reliability (McDonald's $\omega$ of 0.716$)$ and were used to build the video game experience variable (video game frequency score doubled for participants reporting playing intensive games). This variable shows a strong reliability with its two components (McDonald's $\omega$ of 0.897 ) and was thus used independently and unitary.

\section{Pearson's Correlations}

Spatial cognition performance was positively correlated to sense of presence ( $r=0.369, p=0.005,95 \%$ CI $[1,0.192])$, negatively correlated to cybersickness $(r=-0.29, p=0.029,95 \%$ CI $[-0.92$, $-1])$, and tended to correlate to video game experience $(r=$ $0.21, p=0.075,95 \%$ CI $[1,-0.032])$. Sense of presence was negatively correlated to cybersickness $(r=-0.27, p=0.031$, $95 \%$ CI $[-0.87,-1])$, and positively correlated to video game experience $(r=0.32, p=0.013,95 \%$ CI $[1,0.09])$. Cybersickness was negatively associated with video game experience $(r=-0.32$, $p=0.013,95 \% \mathrm{CI}[-0.087,-1])$ and with the feminine gender $(r=-0.301, p=0.02,95 \%$ CI $[-0.116,-1])$. Finally, feminine gender was negatively associated but only in a trend manner with video game experience $(r=-0.23, p=0.053,95 \%$ CI [ 1 ,
$-0.005])$ and visual field dependence $(r=-0.24, p=0.055$, $95 \%$ CI $[-0.051,-1])$. Figure 3 illustrates the main correlations split per gender.

\section{Linear Regressions Spatial Cognition Performance}

Sense of presence significantly predicted spatial cognition performance $\left(S E=0.006, \beta=0.389, t_{(45)}=2.749, p=0.009\right.$, $95 \%$ CI $[0.004,0.029])$, along with cybersickness ( $S E=0.024, \beta$ $=-0.404, t_{(45)}=-2.348, p=0.024,95 \%$ CI $\left.[-0.105,-0.008]\right)$ in interaction with gender $\left(S E=0.042, \beta=0.533, t_{(45)}=\right.$ $2.295, p=0.027,95 \%$ CI $[0.012,0.182])$. Gender had no simple effect $(p=0.747)$. This whole model explained a significant part of variance in spatial cognition performance, $R^{2}=0.263$, $F_{(4,42)}=3.739, p=0.011$. Sensitivity test revealed a critical $F$ of 2.59, and post-hoc power analysis revealed an effect size of $f^{2}=0.356$ and a statistical power $=0.890$. In order to explore this association, Pearson's correlations and $t$-tests were used separately between genders and revealed a significant correlation between spatial cognition performance and cybersickness among women $(r=0.50, p=0.013,95 \%$ CI $[-0.122,-0.752])$, but not among men. Similarly, women's raw scores of cybersickness $(6.41 \pm 4.05)$ were significantly higher than those of men $(4.21 \pm 2.96): t_{(45)}=2.11, p=0.04$, Cohen's $d=0.61$, 95\% CI $[0.104,4.294]$.

\section{Sense of Presence}

Video game experience significantly predicted sense of presence $\left(S E=0.048, \beta=0.326, t_{(45)}=2.31, p=0.026,95 \%\right.$ CI $[0.014$, $0.209])$. Video game experience also explained a significant part of variance in sense of presence, $R^{2}=0.106, F_{(1,45)}=5.338, p=$ 0.026 . The sensitivity test revealed a critical $F$ of 4.05 , and post-hoc power analysis revealed an effect size $f^{2}=0.118$ and a statistical power $=0.636$.

\section{Cybersickness}

Video game experience significantly predicted cybersickness (SE $=0.01, \beta=-0.323, t_{(45)}=-2.293, p=0.027,95 \%$ CI $[-0.064$, $-0.004])$. Video game experience also explained a significant proportion of variance in cybersickness, $R^{2}=0.105, F_{(1,45)}=$ $5.256, p=0.027$. The sensitivity test revealed a critical $F$ of 4.05 and post-hoc power analysis revealed an effect size $f^{2}=0.117$ and a statistical power $=0.632$.

\section{Mediation Analysis}

Only cybersickness and video game experience were retained for mediation analysis: being the only two variables correlated to both sense of presence and spatial cognition performance, they were the only two that could potentially mediate the relationship. Neither cybersickness (z-value $=1.01, p=0.312,95 \% \mathrm{CI}$ $[-0.002,0.003])$ nor video game experience $(\mathrm{z}$-value $=0.758, p=$ $0.448,95 \%$ CI $[-0.002,0.004])$ nor both taken altogether (z-value $=1.219, p=0.223,95 \%$ CI $[-0.002,0.007])$ were significant mediators of the relationship between sense of presence and spatial cognition performance. 


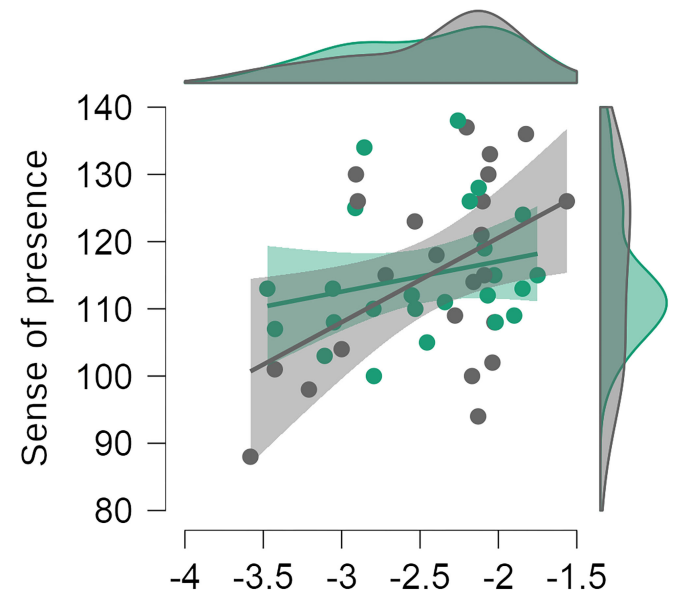

Spatial cognition performance

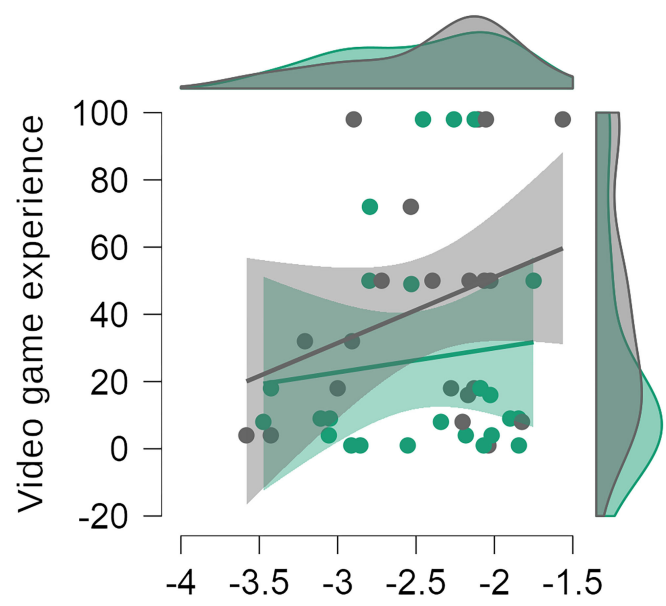

Spatial cognition performance

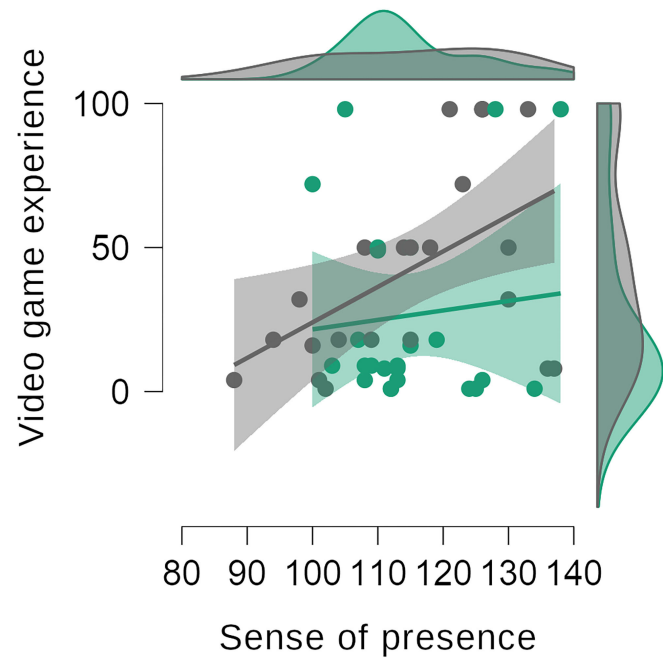

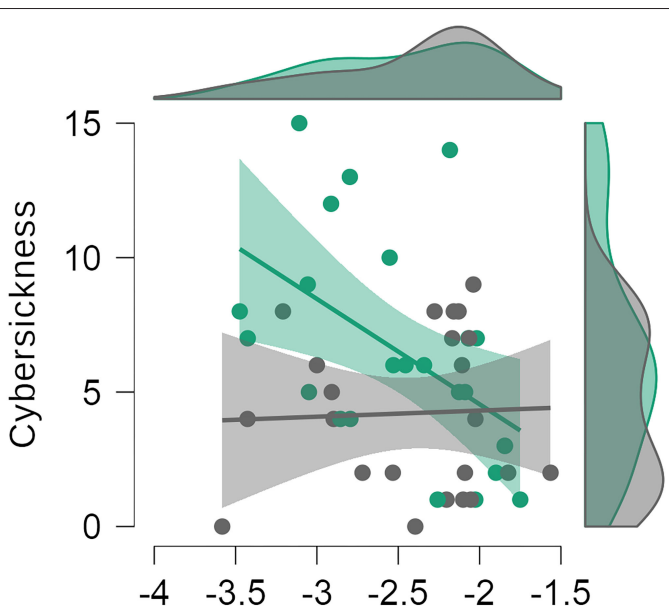

Spatial cognition performance

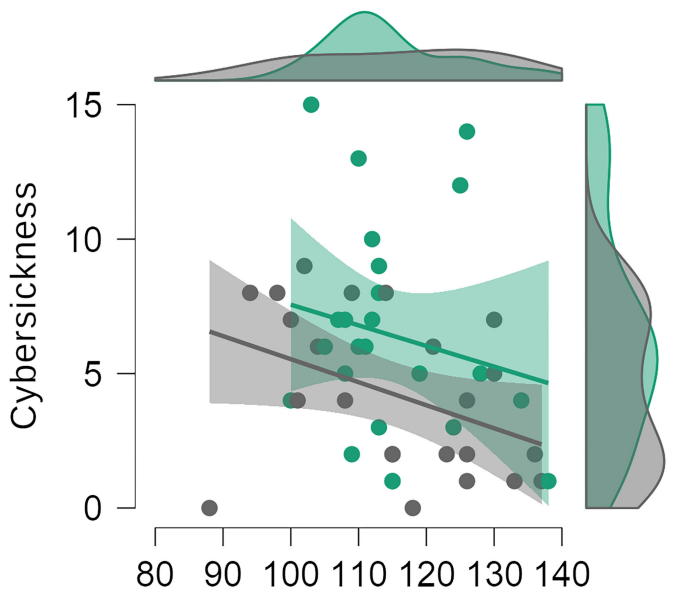

Sense of presence

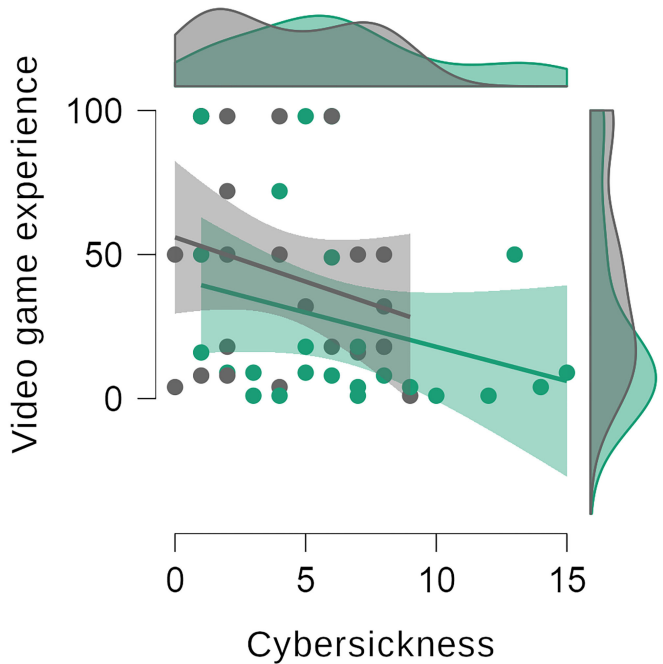

FIGURE 3 | Scatter plots of each variable associations split between genders (green: women; gray: men) including density graph, regression line and confidence interval (95\%). 


\section{DISCUSSION}

\section{Presence and Spatial Cognition}

The main objective of this study was to determine if sense of presence affects task performance on a VR spatial cognition assessment. Empirical results confirm our hypothesis: sense of presence seems to promote spatial cognition performance, probably because of high levels of presence and a joint mutually nourishing allocation of attentional resources toward the environment and the task (Draper et al., 1998). This result is a big step in the understanding of the VR framework. Still, two major questions have to be discussed: the impact of other human factors, and the nature of the sense of presenceperformance relationship. Indeed, what is often suggested when discussing the presence-performance relationship is the potential effects of other variables, amongst which video games experience, cybersickness, gender and field dependence. Considering the experimental data, it is possible to answer that in the current study and on a spatial cognition task, this mediation on performance was not directly significant. However, it would not be parsimonious to assert that these human factors do not affect the outcomes at all. First, along with sense of presence, cybersickness explained a significant part of spatial cognition performance, but only when considered in interaction with gender. This model, which explained more than $25 \%$ of the variance in performance, revealed differences of the impact of negative symptoms between men and women (gender having no effect per itself on performance). Indeed, when considered independently, spatial cognition is strongly and negatively correlated to cybersickness among women, while not correlated at all among men. This effect, which can be visually explored in the scatter plots (Figure 2), is not surprising: negative symptoms only impact performance when they exist or exceed a certain threshold, which is more often found among women than men (Munafo et al., 2017; Shafer et al., 2017; Weech et al., 2019). This effect, which might be explained by the fact that interpupillary distance was not controlled as recommended by Stanney et al. (2020), or by other unmeasured factors presented in introduction, reveal that the interaction is not a matter of modality but of levels. The harmful effects of motion sickness symptoms on cognitive processes are often suggested and tested (Gresty et al., 2008; Gresty and Golding, 2009; Matsangas et al., 2014; Nalivaiko et al., 2015), and might be attributed to the disturbances of attentional resources, for example a recalibration in order to regain postural stability, or to the emergence of body-awareness and stress. Another important result of this study revealing the impact of human factors in VR is the fact that video game experience significantly predicted sense of presence, which itself significantly predicted spatial cognition performance. In addition, video game experience also significantly predicted cybersickness, which itself impacted performance. These associations are, for the most part, suggested independently by different authors, but still require some discussion as they are usually not studied altogether. First, the fact that sense of presence was significantly predicted by video game experience is in accordance with previous studies (Gamito et al., 2008). But its direction remains obscure: are video games more appealing to individuals more prone to presence, or do video games train players to be more susceptible to presence, for example by enhancing their familiarity with the computer interaction? This familiarity could make video game players more at ease in VR, for instance by facilitating the recognition of cognitive schemes or ergonomics processes, leading to more presence by not having to drag their attention to the media that is VR: recall the definition of presence of Lombard and Ditton (1997), the "illusion of non-mediation." To speak in ecological terms, familiarity with video games could make VR affordances more salient. This interpretation would explain why this relationship between sense of presence and video game experience is not systematically found in the literature (Alsina-Jurnet and Gutiérrez-Maldonado, 2010; Weech et al., 2020): when human-computer interaction or knowledge of global processes (or affordances) are too different from what players are used to, this skill transfer cannot happen and thus does not affect the sense of presence. It is also possible that video games, and notably intensive video games, train the players to be more focused on a virtual task and to inhibit non-pertinent stimuli, which is fundamental for the emergence of the sense of presence in VR. Indeed, not only is it necessary to inhibit non-pertinent stimuli from the real world to build a sense of presence, but these skills might also help the inhibition of negative symptoms, reducing cybersickness. For this reason, the fact that cybersickness was significantly and negatively correlated to presence is not surprising and is a common association in the literature (Weech et al., 2019), even though it is uncertain whether presence reduces cybersickness just as it reduces pain (Hoffman et al., 2004), or if cybersickness reduces presence by dragging allocating attentional resources to the physical body. Similarly, the association between video game experience and cybersickness has already been suggested and found (Knight and Arns, 2006; De Leo et al., 2014; Weech et al., 2020): interpretations for this effect might be either that video games are more appealing to people who are less susceptible to cybersickness, or that video games train players to be less susceptible to negative symptoms as they are reduced by habituation (Gavgani et al., 2017; Hildebrandt et al., 2018). It is indeed possible that habituation to sensory mismatch during video game practice trains the player to experience less cybersickness in VR, which in turn promotes the sense of presence. It has to be noted that the negative association between sense of presence and cybersickness was only significantly correlational in nature. It is possible that the locomotion technique and the quality of the VR experiment did not trigger enough negative symptoms, as shown by the low scores of cybersickness, reducing the strength of the impact on the sense of presence below the significance threshold. A larger sample could not only confirm the effects found in this study with a higher statistical power, but also allow for the exploration of more interactional effects. Indeed, among all the interpretation suggested previously, it is probably vain to look for a single explanation. It is much more probable that all these variables contribute in different and mutual ways to form a VR favorable profile, leading to a better user experience, improving the performance. 
Amongst the variables often suggested or found to impact sense of presence and performance in VR, two of them were not very informative in our current study. The first one was visual field dependence, which was not found to be correlated to anything. One possible interpretation for the absence of significant correlation between cybersickness and field dependence in our study is the lack of visual flow: participants were moving by small teleportation and not by linear movement. Experiencing a visual flow in VR while the participant is static significantly increases the impact of (incoherent) visual information on sensory integration, which might trigger differences amongst the two cognitive styles (visual field dependent, visual field independent). A contrario, our experimental virtual environment was relatively poor in visual flow stimulation and incoherencies, which could explain the absence of impact of the field dependence continuum. But this explanation is not coherent with the result from Hecht and Reiner (2007) who found a negative association between sense of objects presence and field dependence in an environment, an association which is not present in our study. It could be argued that the association found in their study was a mediation effect of the one between cybersickness and field dependence, even though it is unlikely that a haptic device presenting virtual objects could trigger negative symptoms. Further studies are necessary to investigate the effect of field dependence in VR, as this dimension which might give some insight about the relationship between sense of presence and cybersickness. The second poorly informative variable is gender. Indeed, beside the fact that women experienced more negative symptoms than men, leading to an interaction between gender and cybersickness on performance for which negative symptoms constitute the true causal effect, no differences were found between men and women on the spatial cognition scores. Contrary to the heuristic knowledge and to some of the spatial cognition literature (Silverman and Eals, 1992; Moffat et al., 1998; Parsons et al., 2004; Levine et al., 2016; Brake and Lacasse, 2018), spatial cognition performance was not significantly lower amongst women in this experiment. This result is not a revolutionary one in the field, as performance is a vague term that encompasses different aspects of spatial cognition. Indeed, men are usually found to be better at tasks requiring survey knowledge (Coluccia and Louse, 2004), cardinal directions (Saucier et al., 2002) or navigation efficiency (Grön et al., 2000). However, Boone et al. (2018) notes that there exists "no systematic sex differences in tasks that can be accomplished with route and landmark knowledge, such as when learning from a map, retracing a learned route, or remembering landmarks along a route," which is corroborated by other studies (Montello et al., 1999; Saucier et al., 2002; Coluccia and Louse, 2004). The spatial cognition tasks described by Boone et al. (2018) fit to many of the current experiment evaluations and explain the absence of gender differences on the spatial cognition performance. Beside the spatial cognition, genders did not significantly differ on the sense of presence either, even though women are sometimes considered to be less susceptible to presence than men (Felnhofer et al., 2012). Similarly, there were no significant differences between men and women on the video game frequency, even though men played tended to play more intensive than women.
This difference in video games genre played, combined with the significant regression showing that video game experience predicts cybersickness, might give some insights to explain why women are more susceptible to VR negative symptoms. Nonethe-less, when considering the negative association between cybersickness and spatial cognition performance, the fact that women experience more negative symptoms than men should be of prime concern. However, this affirmation can be put into perspective: video game experience being a better predictor of cybersickness than gender shows that this effect might be a cultural artifact, very probably explained by differences in daily or developmental activities, and thus susceptible to change. It can then be argued that in our data, gender has little effect per itself beside the cultural differences in gaming, which is a changing cultural trend (Entertainment software association, 2019). The absence of a strong independent gender effect, even if it goes against the experimental hypotheses, is a good thing since it means that this variable is not an inherent VR bias. On the other side, our study highlights that video game experience, cybersickness and sense of presence have to be systematically controlled for rigorous evaluations in VR. Of note, further studies assessing for video game experience are necessary to investigate if other variables might turn gender into an impactful variable in VR. For instance, a sample constituted by women with video game experience similar to men (both in term of frequency and genre) could bring a lot of light on these questions. However, considering our data, we can affirm that gender has little effect per se in VR, at least in this case of a spatial cognition task. We can finally propose an answer to "Is virtual reality for men only? Exploring gender differences in the sense of presence" (Felnhofer et al., 2012): no it is not, but it still favors some people more than others.

\section{About the Presence-Performance Relationship}

It is often argued in the VR literature that a causal direction cannot be determined between the sense of presence and the task performance, and that both may be mutually nourishing. The perfect example is the fictive setup of catching virtual balls described previously. In this very integrated sensorimotor task, catching the balls means an improved task performance, but also the realization of continuous interactions with sensorimotor feedbacks that in turn enhance the sense of presence. Considering this, it is pertinent to ask if presence promotes performance, or if performance promotes presence (Nash et al., 2000). Indeed, interactions with the environment are often considered as central to the emergence of spatial presence. Some authors even argued that the phenomenon is a bi-dimensional construct based on the interaction between the feeling of being located somewhere and the ability to interact with this "somewhere" (Wirth et al., 2007).

In our current experiment, even though the task was deeply integrated into the environment, the imbrication between performance evaluation and sensorimotor interactions were not as straightforward: participants had no feedback on their performance and did not know the exact modalities of the 
evaluation until the very end of the experiment. One interesting point is that spatial cognition was evaluated via the headmounted display, inside the virtual environment, which might have helped more present subjects to recall by not "leaving" the virtual place: it is known that recalling abilities are enhanced when the recalling context is similar to the learning context (Smith and Vela, 2001). Schwind et al. (2019) recommend, for similar reasons, to use presence questionnaires in VR for more accurate evaluation, as we did with the spatial cognition performance. However, it is still to some extent arguable that feeling self-efficient during the navigation triggered more involvement and thus more presence by allocation of supplementary attentional resources. But it seems parsimonious to state that experiencing more spatial presence helped the elaboration and encoding of cognitive maps and later the recalling and recognition of spatial information (Madl et al., 2015; Epstein et al., 2017). The main question here is the procedural aspect. When does presence occur? In their process model of the formation of spatial presence, Wirth et al. (2007) argued that a modeling of the spatial situation is necessary for the emergence of spatial presence, and that this model of spatial situation is largely based on spatial cues and information. Their model is procedural; the spatial situation representation constitutes the first level, and the formation of spatial presence the second level. Coherently, one could argue that some participants allocated more (or better) attentional resources toward the environment and its perceptive cues, enhancing their spatial cognition evaluation on one side and their presence on the other side via a richer first level spatial model. In these views, spatial cognition cannot be influenced by the sense of presence, since it precedes its emergence. At best, they share a common first level base. The only possible argument here for presence to promote spatial cognition performance would be that being more present helped the contextual or emotional recalling of spatial cognition and representations, but not their processing (Lee and Sternthal, 1999; Smith and Vela, 2001; Nadler et al., 2010).

Thus, if we consider presence as a second level phenomenon resulting from the perceptive, cognitive and motor processing in the virtual environment, then it does not and cannot affect spatial cognition performance beyond mere involvement or learning enhancement aspects. However, others views of cognition are worth discussing since they might reverse the spatial cognition and performance relationship. The ecological theories of cognition, sometimes called enactivist or embedded theories (Thompson, 2007; Rowlands, 2010; Lobo et al., 2018), consider that cognition emerges through a continuous interaction between an acting organism and its environment. Inspired by psychologists like Gibson, phenomenologists like Merleau-Ponty or philosophers like Heidegger, these views consider representations as secondary or even inexistent, and cognition-perception directed toward the ability to act, called affordances (Gibson, 1977, 1979). Applying the sense of presence to ecological theories, authors have suggested the sense of presence as a fundamental part of consciousness and even an evolutionary process to distinguish the individual from the environment (Zahorik and Jenison, 1998; Mantovani and Riva, 1999; Riva and Waterworth, 2003; Riva, 2006; Coelho et al., 2009). In this case, there is no first level modeling of spatial representation, only different components of "being-inthe-world," like the sense of embodiment, the sense of agency, the sense of self-awareness or the sense of presence (Schultze, 2010; Kilteni et al., 2012; Moore, 2016; Braun et al., 2018). Presence, as a psychological construct, would emerge from the interaction with the environment and the perception of affordances in it (Grabarczyk and Pokropski, 2016). It is based on these affordances that individuals build their perception of their surroundings and their sense of presence. Thus, there can be no spatial cognition without a prime sense of presence. Indeed, in these views, since the sense of presence emerges from the core of experience it does not follow spatial cognition but, to some degree, induce it. Just as the perceptual, motor and cognitive systems relationship is constitutive and not causal in the ecological views (Adams, 2010; Mahon, 2015; Sullivan, 2018), so might be the sense of presence and spatial performance relationship.

Before concluding with these theoretical discrepancies about the presence-performance relationship, it is important to note that our experimental data do not allow us to answer this question or to choose one theoretical framework over another. Indeed, and beyond the relatively low sample, more specifically developed protocols are needed to answer this question, so we can only hope that this discussion will stimulate and help future research on this fundamental question. Now, let us extend the fictive VR balls catching game described previously. In traditional representational views, the individuals will, based on spatial representation, build a sense of presence. Then, when asked to catch virtual balls, they might show a poorer performance when there is a delay between their physical movement and their avatar movement for ergonomics sensorimotor reasons. This delay will foster cybersickness because of incongruences in perceived information and interned representation, dragging attentional resources to the physical body and not the virtual environment thus inhibiting presence. This effect might be mitigated by a habituation due to video game experience. On another side, being good at catching the balls might enhance the sense of presence by adding interaction and involvement via selfperceived performance, but only in a procedural way, notably via retro-action loops that might be related to the perceptual testing described by Wirth et al. (2007). In ecological views, this whole experience is constitutive; both the sense of presence and performance will emerge from the ability to interact with the environment in which perception is enhanced by video game experience and altered by cybersickness in case of poor quality. In these views, before performing, one has to perceive the ability to interact with the object of performance, and by doing so, feels present in the environment. Thus, in an ecological framework, the question of causality direction between performance and presence is, to some extent, irrelevant.

\section{Conclusion}

The main result of this study is the model, constituted by sense of presence and cybersickness, which explained more than $25 \%$ of variance in the VR spatial cognition performance. This association between sense of presence, cybersickness and 
spatial cognition performance is a big step for the global comprehension of the VR framework, both theoretically and methodologically, which is discussed as a joint and mutually nourishing allocation of attentional resources toward the virtual environment and task. A secondary but just as important result is the fact that video game experience is a significant predictor of sense of presence, discussed as an increased familiarity with the interaction, the recognition of cognitive schemes or the trained inhibition of non-pertinent stimuli, which allows for a better allocation of attentional resources. The training aspect of video games, notably on the perceptive mismatch habituation, is also discussed as an explanation as to why cybersickness was significantly predicted by video game experience, and not the gender variable. The gender interaction with cybersickness on performance is discussed as an artifact of the male-dominated gaming culture, relativizing its impact in VR equations. Even if the presence-performance causality is still arguable depending on the nature of the sense of presence and the theoretical framework used, the strength of the association has to be considered by actors and researchers of VR. We defend in this paper the idea that confronting traditional representational views and ecological views of cognition leads to beneficial contribution to the field of presence and more broadly to VR theories and applications. Concerning the impact of human factors, sense of presence, video game experience and cybersickness, should probably not be considered as the only three dimensions of the VR favorable cognitive-perceptive profile, but rather as a measurable manifestation of it, and that many others need to be investigated by future studies. For example, if field dependence had no effect in this study, this might be different in a visually stimulating environment. Indeed, it has to be noted that the impact of this profile, just as the association between presence and performance, very probably depend on the nature of the task. Similarly to what Draper et al. (1998) suggested, the economy of attentional resources between performance and presence might depend on the degree by which the task is integrated into the virtual environment. This could explain why the level of significance we found on a spatial cognition evaluation, a task sharing many processes with the spatial presence, is not always reproduced in the literature. Future studies are necessary to investigate the strength of this modulation. Considering the many different uses and forms that human performance can take, reproducing this kind of analysis with different tasks

\section{REFERENCES}

Adams, F. (2010). Embodied cognition. Phenomenol. Cogn. Sci. 9, 619-628. doi: $10.1007 /$ s11097-010-9175-x

Allahyar, M., and Hunt, E. (2003). The assessment of spatial orientation using virtual reality techniques. Int. J. Test. 3, 263-275. doi: 10.1207/S15327574IJT0303_5

Allison, S. L., Fagan, A. M., Morris, J. C., and Head, D. (2016). Spatial navigation in preclinical Alzheimer's disease. J. Alzheimer's Dis. 52, 77-90. doi: 10.3233/JAD-150855

Alsina-Jurnet, I., and Gutiérrez-Maldonado, J. (2010). Influence of personality and individual abilities on the sense of presence experienced in anxiety triggering virtual environments. Int. J. Hum. Comput. Stud. 68, 788-801. doi: $10.1016 /$ j.ijhcs.2010.07.001 (or comparing virtual vs. real neuropsychological tasks) should be helpful for the global framework of VR, and notably its applications in research and health. Indeed, controlling for this VR favorable profile, and notably the video game experience, might end up being mandatory when using VR to assess human performance if one wants to use a methodologically rigorous tool. Finally, it might be time to call for a standardization of VR psychological tasks, in order to propose a large scale sample which could be used as a normalization tool with the aim of sharing this technology's benefits as widely as possible. Indeed, researchers and other actors of the field should keep in mind that VR is not only a transposition of reality but truly is a new paradigm, and until the media becomes fully "invisible to the subject," it still has its own biases impacting different users in different ways.

\section{DATA AVAILABILITY STATEMENT}

The raw data supporting the conclusions of this article will be made available by the authors, without undue reservation.

\section{ETHICS STATEMENT}

The studies involving human participants were reviewed and approved by Comité d'éthique de la recherche en éducation et en psychologie (CEREP). The patients/participants provided their written informed consent to participate in this study.

\section{AUTHOR CONTRIBUTIONS}

$\mathrm{AM}$ and PR designed the experiment. AM reviewed the literature, wrote the manuscript, programmed the virtual environment, done the participants recruitment, data gathering, and preliminary treatment. $\mathrm{AM}$ and $\mathrm{PF}$ organized the experimental procedure. AM, PR, LD, and $\mathrm{HC}$ treated and discussed the empirical results. All authors discussed and reviewed the manuscript.

\section{ACKNOWLEDGMENTS}

The authors would like to thank the Plan de Rome project's team (S. Madeleine, N. Lefevre, C. Morineau, A. Tellier, and J. Nicolle) for their help in the building of the virtual environment.

Baniqued, P. L., Lee, H., Voss, M. W., Basak, C., Cosman, J. D., DeSouza, S., et al. (2013). Selling points: what cognitive abilities are tapped by casual video games? Acta Psychol. 142, 74-86. doi: 10.1016/j.actpsy.2012.11.009

Barfield, W., and Hendrix, C. M. (1995). The effect of update rate on the sense of presence within virtual environments. Virtual Real. 1, 3-15. doi: 10.1007/BF02009709

Barfield, W., Zeltzer, D., Sheridan, T., and Slater, M. (1995). "Virtual environments and advanced interface design," in Presence and Performance within Virtual Environments, eds W. Barfield, and T. A. Furness III (New York, NY: Oxford University Press, Inc), 473-513.

Behm-Morawitz, E., and Mastro, D. (2009). The effects of the sexualization of female video game characters on gender stereotyping and female self-concept. Sex Roles 61, 808-823. doi: 10.1007/s11199-0099683-8 
Bohil, C. J., Alicea, B., and Biocca, F. A. (2011). Virtual reality in neuroscience research and therapy. Nat. Rev. Neurosci. 12, 752-762. doi: 10.1038/nrn3122

Boone, A. P., Gong, X., and Hegarty, M. (2018). Sex differences in navigation strategy and efficiency. Mem. Cognit. 46, 909-922. doi: 10.3758/s13421-018-0811-y

Boot, W. R., Blakely, D. P., and Simons, D. J. (2011). Do action video games improve perception and cognition? Front. Psychol. 2:226. doi: 10.3389/fpsyg.2011.00226

Bos, J. E., Bles, W., and Groen, E. L. (2008). A theory on visually induced motion sickness. Displays 29, 47-57. doi: 10.1016/j.displa.2007.09.002

Bos, J. E., MacKinnon, S. N., and Patterson, A. (2005). Motion sickness symptoms in a ship motion simulator: effects of inside, outside, and no view. Aviat. Space Environ. Med. 76, 1111-1118.

Bosser, A.-G., and Nakatsu, R. (2006). "Hardcore gamers and casual gamers playing online together," in Proceedings of the 5th International Conference on Entertainment Computing (Cambridge: Springer-Verlag), 374-377.

Bouchard, S., Robillard, G., and Renaud, P. (2007). Revising the factor structure of the simulator sickness questionnaire. Acte de colloque du Annual Review of CyberTherapy and Telemedicine 5, 117-122.

Boyle, E. A., Hainey, T., Connolly, T. M., Gray, G., Earp, J., Ott, M., et al. (2016). An update to the systematic literature review of empirical evidence of the impacts and outcomes of computer games and serious games. Comput. Educ. 94, 178-192. doi: 10.1016/j.compedu.2015.11.003

Brake, W. G., and Lacasse, J. M. (2018). Sex differences in spatial navigation: the role of gonadal hormones. Curr. Opin. Behav. Sci. 23, 176-182. doi: 10.1016/j.cobeha.2018.08.002

Braun, N., Debener, S., Spychala, N., Bongartz, E., Sörös, P., Müller, H. H. O., et al. (2018). The senses of agency and ownership: a review. Front. Psychol. 9:535. doi: $10.3389 /$ fpsyg.2018.00535

Breuer, J., Kowert, R., Festl, R., and Quandt, T. (2015). Sexist games=sexist gamers? A longitudinal study on the relationship between video game use and sexist attitudes. Cyberpsychol. Behav. Soc. Netw. 18, 197-202. doi: 10.1089/cyber.2014.0492

Byagowi, A., and Moussavi, Z. (2012). "Design of a Virtual Reality Navigational (VRN) experiment for assessment of egocentric spatial cognition," in Conference Proceedings: Annual International Conference of the IEEE Engineering in Medicine and Biology Society (San Diego, CA: IEEE Engineering in Medicine and Biology Society), 4812-4815.

Bystrom, K.-E., Barfield, W., and Hendrix, C. (1999). A conceptual model of the sense of presence in virtual environments. Presence 8, 241-244. doi: $10.1162 / 105474699566107$

Cameron, E. L. (2014). Pregnancy and olfaction: a review. Front. Psychol. 5:67. doi: 10.3389 /fpsyg.2014.00067

Castelvecchi, D. (2016). Low-cost headsets boost virtual reality's lab appeal. Nature 533, 153-154. doi: 10.1038/533153a

Cipresso, P., Giglioli, I. A. C., Raya, M. A., and Riva, G. (2018). The past, present, and future of virtual and augmented reality research: a network and cluster analysis of the literature. Front. Psychol. 9:2086. doi: 10.3389/fpsyg.2018. 02086

Cipresso, P., Serino, S., and Riva, G. (2016). Psychometric assessment and behavioral experiments using a free virtual reality platform and computational science. BMC Med. Inform. Decis. Mak. 16:37. doi: 10.1186/s12911-016-0276-5

Clay, F., Howett, D., FitzGerald, J., Fletcher, P., Chan, D., and Price, A. (2020). Use of immersive virtual reality in the assessment and treatment of alzheimer's disease: a systematic review. J. Alzheimer's Dis. 75, 23-43. doi: 10.3233/JAD-191218

Clemes, S. A., and Howarth, P. A. (2005). The menstrual cycle and susceptibility to virtual simulation sickness. J. Biol. Rhythms 20, 71-82. doi: $10.1177 / 0748730404272567$

Clifton, J., and Palmisano, S. (2019). Effects of steering locomotion and teleporting on cybersickness and presence in HMD-based virtual reality. Virtual Real. 24, 453-468. doi: 10.1007/s10055-019-00407-8

Coelho, C., Tichon, J., Hine, T. J., Wallis, G., and Riva, G. (2009). "Media presence and inner presence: the sense of presence in virtual reality technologies," in From Communication to Presence: Cognition, Emotions and Culture Towards the Ultimate Communicative Experience: Festschrift in Honor of Luigi Anolli, Vol. 9, eds G. Riva, M. T. Anguera, B. K. Wiederhold, and F. Mantovani (Amsterdam: Ios Press), 25-45.
Cogné, M, Auriacombe, S., Vasa, L., Tison, F., Klinger, E., Sauzéon, H., et al. (2018). Are visual cues helpful for virtual spatial navigation and spatial memory in patients with mild cognitive impairment or Alzheimer's disease? Neuropsychology 32, 385-400. doi: 10.1037/neu0000435

Cogné, M., Taillade, M., N’Kaoua, B., Tarruella, A., Klinger, E., Larrue, F., et al. (2017). The contribution of virtual reality to the diagnosis of spatial navigation disorders and to the study of the role of navigational aids: a systematic literature review. Ann. Phys. Rehabil. Med. 60, 164-176. doi: 10.1016/j.rehab.2015. 12.004

Coleman, B., Marion, S., Rizzo, A., Turnbull, J., and Nolty, A. (2019). Virtual reality assessment of classroom - related attention: an ecologically relevant approach to evaluating the effectiveness of working memory training. Front. Psychol. 10:1851. doi: 10.3389/fpsyg.2019.01851

Coluccia, E., and Louse, G. (2004). Gender differences in spatial orientation: a review. J. Environ. Psychol. 24, 329-340. doi: 10.1016/j.jenvp.2004.08.006

Cooper, N., Milella, F., Pinto, C., Cant, I., White, M., and Meyer, G. (2018). The effects of substitute multisensory feedback on task performance and the sense of presence in a virtual reality environment. PLoS ONE 13:e191846. doi: 10.1371/journal.pone.0191846

Cushman, L. A., Stein, K., and Duffy, C. J. (2008). Detecting navigational deficits in cognitive aging and Alzheimer disease using virtual reality. Neurology 71 , 888-895. doi: 10.1212/01.wnl.0000326262.67613.fe

De Leo, G., Diggs, L. A., Radici, E., and Mastaglio, T. W. (2014). Measuring sense of presence and user characteristics to predict effective training in an online simulated virtual environment. Simul. Healthc. 9, 1-6. doi: 10.1097/SIH.0b013e3182a99dd9

Diersch, N., and Wolbers, T. (2019). The potential of virtual reality for spatial navigation research across the adult lifespan. J. Exp. Biol. 222(Suppl. 1):jeb187252. doi: $10.1242 /$ jeb.187252

Draper, J. V., and Blair, L. M. (1996). "Workload, flow, and telepresence during teleoperation," in Proceedings of IEEE International Conference on Robotics and Automation (Minneapolis, MN: IEEE).

Draper, J. V., Kaber, D. B., and Usher, J. M. (1998). Telepresence. Hum. Factors 40, 354-375. doi: 10.1518/001872098779591386

Entertainment software association (2019). Essential Facts about The Computer and Video Game Industry. Entertainment software association.

Entertainment Software Association (2019). 2019 Sales, Demographic and Usage Data - Essential Facts About the Computer and Video Game Industry. Available online at: https://www.theesa.com/esa-research/2019-essential-factsabout-the-computer-and-video-game-industry/

Epstein, R. A., Patai, E. Z., Julian, J. B., and Spiers, H. J. (2017). The cognitive map in humans: spatial navigation and beyond. Nat. Neurosci. 20, 1504-1513. doi: $10.1038 / \mathrm{nn} .4656$

Evans, C., Richardson, J. T. E., and Waring, M. (2013). Field independence: reviewing the evidence. Br. J. Educ. Psychol. 83(Pt 2), 210-224. doi: 10.1111/bjep.12015

Felnhofer, A., Kothgassner, O., Beutl, L., Hlavacs, H., and Kryspin-Exner, I. (2012). "Is virtual reality made for men only? exploring gender differences in the sense of presence," in Proceedings of the International Society on Presence Research (Philadelphia, PA: International Society for Presence Research), 103-112.

Feng, J., Spence, I., and Pratt, J. (2016). Playing an action video game reduces gender differences in spatial cognition. Psychol. Sci. 18, 850-855. doi: $10.1111 / j .1467-9280.2007 .01990 . x$

Foreman, N. (2010). Virtual reality in psychology. Themes Sci. Tech. Educ. $2,225-252$.

Fox, J., and Potocki, B. (2016). Lifetime video game consumption, interpersonal aggression, hostile sexism, and rape myth acceptance: a cultivation perspective. J. Interpers. Violence 31, 1912-1931. doi: 10.1177/0886260515 570747

Gamito, P., Oliveira, J., Morais, D., Baptista, A., Santos, N., Soares, F., et al. (2010). Training presence: the importance of virtual reality experience on the « sense of being there. Stud. Health Technol. Inform. 154, 128-133.

Gamito, P., Oliveira, J., Morais, D., Santos, N., and Soares, F. (2008). Presence, immersion and cybersickness assessment through a test anxiety virtual environment. Ann. Rev. Cyberther. Telemed. 83-90.

Gavgani, A. M., Nesbitt, K. V., Blackmore, K. L., and Nalivaiko, E. (2017). Profiling subjective symptoms and autonomic changes associated with cybersickness. Auton. Neurosci. 203, 41-50. doi: 10.1016/j.autneu.2016.12.004 
Gibson, J.-J. (1977). "How perception really develops: a view from outside the network," in Basic Processes in Reading : Perception and Comprehension, (Boston, MA: Erlbaum), 155-173.

Gibson, J.-J. (1979). The Ecological Approach to Visual Perception. Houghton Mifflin Harcourt.

Grabarczyk, P., and Pokropski, M. (2016). Perception of affordances and experience of presence in virtual reality. AVANT 7, 25-44. doi: 10.26913/70202016.0112.00

Green, C. S., and Bavelier, D. (2003). Action video game modifies visual selective attention. Nature 423, 534-537. doi: 10.1038/nature01647

Green, C. S., and Bavelier, D. (2006). Effect of action video games on the spatial distribution of visuospatial attention. J. Exp. Psychol. Hum. Percept. Perform. 32, 1465-1478. doi: 10.1037/0096-1523.32.6.1465

Green, C. S., and Bavelier, D. (2007). Action-video-game experience alters the spatial resolution of vision. Psychol. Sci. 18, 88-94. doi: 10.1111/j.1467-9280.2007.01853.x

Gregg, L., and Tarrier, N. (2007). Virtual reality in mental health. Soc. Psychiatry Psychiatr. Epidemiol. 42, 343-354. doi: 10.1007/s00127-007-0173-4

Gresty, M. A., and Golding, J. F. (2009). Impact of vertigo and spatial disorientation on concurrent cognitive tasks. Ann. N. Y. Acad. Sci. 1164, 263-267. doi: 10.1111/j.1749-6632.2008.03744.x

Gresty, M. A., Golding, J. F., Le, H., and Nightingale, K. (2008). Cognitive impairment by spatial disorientation. Aviat. Space Environ. Med. 79, 105-111. doi: $10.3357 /$ asem.2143.2008

Grön, G., Wunderlich, A. P., Spitzer, M., Tomczak, R., and Riepe, M. W. (2000). Brain activation during human navigation: gender-different neural networks as substrate of performance. Nat. Neurosci. 3, 404-408. doi: 10.1038/73980

Hecht, D., and Reiner, M. (2007). Field dependency and the sense of objectpresence in haptic virtual environments. Cyberpsychol. Behav. 10, 243-251. doi: $10.1089 / \mathrm{cpb} .2006 .9962$

Heeter, C. (1992). Being there: the subjective experience of presence. Presence 1, 262-271. doi: 10.1162/pres.1992.1.2.262

Hildebrandt, J., Schmitz, P., Calero Valdez, A., Kobbelt, L., and Ziefle, M. (2018). "Get well soon! human factors' influence on cybersickness after redirected walking exposure in virtual reality," in Virtual, Augmented and Mixed Reality: Interaction, Navigation, Visualization, Embodiment, and Simulation, eds J. Y. C. Chen, and G. Fragomeni (Las Vegas, NV: Springer International Publishing), 82-101.

Hoeft, F., Watson, C. L., Kesler, S. R., Bettinger, K. E., and Reiss, A. L. (2008). Gender differences in the mesocorticolimbic system during computer gameplay. J. Psychiatr. Res. 42, 253-258. doi: 10.1016/j.jpsychires.2007.11.010

Hoffman, H. G., Sharar, S. R., Coda, B., Everett, J. J., Ciol, M., Richards, T., et al. (2004). Manipulating presence influences the magnitude of virtual reality analgesia. Pain 111, 162-168. doi: 10.1016/j.pain.2004.06.013

Howarth, P. A., and Hodder, S. G. (2008). Characteristics of habituation to motion in a virtual environment. Displays 29, 117-123. doi: 10.1016/j.displa.2007.09.009

Ijaz, K., Ahmadpour, N., Naismith, S. L., and Calvo, R. A. (2019). An immersive virtual reality platform for assessing spatial navigation memory in predementia screening: feasibility and usability study. JMIR Ment. Health 6:e13887. doi: $10.2196 / 13887$

Jones, C., Scholes, L., Johnson, D., Katsikitis, M., and Carras, M. C. (2014). Gaming well: links between videogames and flourishing mental health. Front. Psychol. 5:260. doi: 10.3389/fpsyg.2014.00260

Juul, J. (2010). A Casual Revolution: Reinventing Video Games and Their Players. Cambridge MA: MIT Press.

Kapalo, K. A., Dewar, A. R., Rupp, M. A., and Szalma, J. L. (2015). Individual differences in video gaming: defining hardcore video gamers. Proc. Hum. Factors Ergon. Soc. Annu. Meet. 59, 878-881. doi: 10.1177/1541931215591261

Kennedy, R. S. (1975). Motion sickness questionnaire and field independence scores as predictors of success in naval aviation training. Aviat. Space Environ. Med. 46, 1349-1352.

Kennedy, R. S., Lane, N. E., Berbaum, K. S., and Lilienthal, M. G. (1993). Simulator sickness questionnaire: an enhanced method for quantifying simulator sickness. Int. J. Aviat. Psychol. 3, 203-220. doi: 10.1207/s15327108ijap 0303_3

Kilteni, K., Groten, R., and Slater, M. (2012). The sense of embodiment in virtual reality. Presence 21, 373-387. doi: 10.1162/PRES_a_00124
Kim, O., Pang, Y., and Kim, J.-H. (2019). The effectiveness of virtual reality for people with mild cognitive impairment or dementia: a meta-analysis. BMC Psychiatry 19:219. doi: 10.1186/s12888-019-2180-x

Knight, M. M., and Arns, L. L. (2006). The Relationship Among Age and Other Factors on Incidence of Cybersickness in Immersive Environment Users. (Boston, MA: ACM SIGGRAPH 2006 Research Posters).

Kowert, R., Breuer, J., Quandt, T., Breuer, J., and Quandt, T. (2017). Women Are From Farm Ville, Men Are From ViceCity: The Cycle of Exclusion and Sexism in Video Game Content and Culture. New Perspectives on the Social Aspects of Digital Gaming (New York, NY: Routledge).

Kuittinen, J., Kultima, A., Niemelä, J., and Paavilainen, J. (2007). "Casual games discussion," in Proceedings of the 2007 Conference on Future Play (New York, NY: Association for Computing Machinery), 105-112.

Lachlan, K., and Krcmar, M. (2011). Experiencing presence in video games: the role of presence tendencies, game experience, gender, and time spent in play. Commun. Res. Rep. 28, 27-31. doi: 10.1080/08824096.2010.518924

LaViola, J. J. (2000). A discussion of cybersickness in virtual environments. ACM SIGCHI Bull 32, 47-56. doi: 10.1145/333329.333344

Lee, A. Y., and Sternthal, B. (1999). The effects of positive mood on memory. J. Cons. Res. 26, 115-127. doi: 10.1086/209554

Levine, S. C., Foley, A., Lourenco, S., Ehrlich, S., and Ratliff, K. (2016). Sex differences in spatial cognition: advancing the conversation. WIREs Cogn. Sci. 7, 127-155. doi: 10.1002/wcs. 1380

Ling, Y., Nefs, H. T., Brinkman, W.-P., Qu, C., and Heynderickx, I. (2013). The relationship between individual characteristics and experienced presence. Comput. Human Behav. 29, 1519-1530. doi: 10.1016/j.chb.2012.12.010

Lobo, L., Heras-Escribano, M., and Travieso, D. (2018). The history and philosophy of ecological psychology. Front. Psychol. 9:2228. doi: 10.3389/fpsyg.2018.02228

Lombard, M., and Ditton, T. (1997). At the heart of it all: the concept of presence. J. Comp. Med. Commun. 3:JCMC321. doi: 10.1111/j.1083-6101.1997.tb00072.x

Ma, R., and Kaber, D. B. (2006). Presence, workload and performance effects of synthetic environment design factors. Int. J. Hum. Comput. Stud. 64, 541-552. doi: 10.1016/j.ijhcs.2005.12.003

Madl, T., Chen, K., Montaldi, D., and Trappl, R. (2015). Computational cognitive models of spatial memory in navigation space: a review. Neural Netw. 65, 18-43. doi: 10.1016/j.neunet.2015.01.002

Mahon, B. Z. (2015). What is embodied about cognition? Lang. Cogn. Neurosci. 30, 420-429. doi: 10.1080/23273798.2014.987791

Mantovani, G., and Riva, G. (1999). "Real" presence: how different ontologies generate different criteria for presence, telepresence, and virtual presence. Presence 8, 540-550. doi: 10.1162/105474699566459

Matsangas, P., McCauley, M. E., and Becker, W. (2014). The effect of mild motion sickness and sopite syndrome on multitasking cognitive performance. Hum. Factors 56, 1124-1135. doi: 10.1177/0018720814522484

Minderer, M., Harvey, C. D., Donato, F., and Moser, E. I. (2016). Virtual reality explored. Nature 533, 324-325. doi: 10.1038/nature17899

Moffat, S. D., Hampson, E., and Hatzipantelis, M. (1998). Navigation in a "Virtual" maze: sex differences and correlation with psychometric measures of spatial ability in humans. Evol. Hum. Behav. 19, 73-87. doi: 10.1016/S1090-5138(97)00104-9

Montello, D. R., Lovelace, K. L., Golledge, R. G., and Self, C. M. (1999). Sexrelated differences and similarities in geographic and environmental spatial abilities. Ann. Assoc. Am. Geograph. 89, 515-534. doi: 10.1111/0004-5608. 00160

Moore, J. W. (2016). What is the sense of agency and why does it matter? Front. Psychol. 7:1272. doi: 10.3389/fpsyg.2016.01272

Munafo, J., Diedrick, M., and Stoffregen, T. A. (2017). The virtual reality headmounted display Oculus Rift induces motion sickness and is sexist in its effects. Exp. Brain Res. 235, 889-901. doi: 10.1007/s00221-016-4846-7

Murias, K., Kwok, K., Castillejo, A. G., Liu, I., and Iaria, G. (2016). The effects of video game use on performance in a virtual navigation task. Comput. Hum. Behav. 58, 398-406. doi: 10.1016/j.chb.2016.01.020

Nadler, R. T., Rabi, R., and Minda, J. P. (2010). Better mood and better performance: learning rule-described categories is enhanced by positive mood. Psychol. Sci. 21, 1770-1776. doi: 10.1177/0956797610387441

Nalivaiko, E., Davis, S. L., Blackmore, K. L., Vakulin, A., and Nesbitt, K. V. (2015). Cybersickness provoked by head-mounted display affects cutaneous 
vascular tone, heart rate and reaction time. Physiol. Behav. 151, 583-590. doi: 10.1016/j.physbeh.2015.08.043

Nash, E. B., Edwards, G. W., Thompson, J. A., and Barfield, W. (2000). A review of presence and performance in virtual environments. Int. J. Hum. Comput. Interact. 12, 1-41. doi: 10.1207/S15327590IJHC1201_1

Navon, D., and Gopher, D. (1979). On the economy of the human-processing system. Psychol. Rev. 86, 214-255. doi: 10.1037/0033-295X.86.3.214

North, M. M., and North, S. (2016). A comparative study of sense of presence of traditional virtual reality and immersive environments. Austr. J. Inform. Syst. 20. doi: 10.3127/ajis.v20i0.1168

Oliveira, J., Gamito, P., Alghazzawi, D. M., Fardoun, H. M., Rosa, P. J., Sousa, T., et al. (2017). Performance on naturalistic virtual reality tasks depends on global cognitive functioning as assessed via traditional neurocognitive tests. Appl. Neuropsychol. Adult 25, 555-561. doi: 10.1080/23279095.2017.1349661

Pallamin, N., and Bossard, C. (2016). Presence, behavioural realism and performances in driving simulation. IFAC Papersonline 49, 408-413. doi: $10.1016 /$ j.ifacol.2016.10.600

Pallavicini, F., Ferrari, A., and Mantovani, F. (2018). Video games for wellbeing: a systematic review on the application of computer games for cognitive and emotional training in the adult population. Front. Psychol. 9:2127. doi: 10.3389/fpsyg.2018.02127

Pan, X., and Hamilton, A. F. de. C. (2018). Why and how to use virtual reality to study human social interaction: The challenges of exploring a new research landscape. Br. J. Psychol. 109, 395-417. doi: 10.1111/bjop.12290

Parsons, T. D. (2015). Virtual reality for enhanced ecological validity and experimental control in the clinical, affective and social neurosciences. Front. Hum. Neurosci. 9:660. doi: 10.3389/fnhum.2015.00660

Parsons, T. D., Gaggioli, A., and Riva, G. (2017). Virtual reality for research in social neuroscience. Brain Sci. 7:42. doi: 10.3390/brainsci7040042

Parsons, T. D., Larson, P., Kratz, K., Thiebaux, M., Bluestein, B., Buckwalter, J. G., et al. (2004). Sex differences in mental rotation and spatial rotation in a virtual environment. Neuropsychologia 42, 555-562. doi: 10.1016/j.neuropsychologia.2003.08.014

Pausch, R., Pausch, R., Proffitt, D., and Williams, G. (1997). "Quantifying immersion in virtual reality," in Proceedings of the 24th Annual Conference on Computer Graphics and Interactive Techniques (New York, NY: ACM Press/Addison-Wesley Publishing Co.), 13-18.

Pithers, R. (2002). Cognitive learning style: a review of the field dependentfield independent approach. J. Vocat. Educ. Train. 54, 117-132. doi: 10.1080/13636820200200191

Profet, M. (1992). "Pregnancy sickness as adaptation: a deterrent to maternal ingestion of teratogens," in The Adapted Mind: Evolutionary Psychology and the Generation of Culture, eds J. H. Barkow, L. Cosmides, J. Tooby (New York, NY: Oxford University Press) 327-365.

Reason, J., and Brand, J. J. (1975). Motion Sickness. London: Academic Press Inc.

Rebenitsch, L., and Owen, C. (2016). Review on cybersickness in applications and visual displays. Virtual Real. 20, 101-125. doi: 10.1007/s10055-016-0285-9

Rehbein, F., Staudt, A., Hanslmaier, M., and Kliem, S. (2016). Video game playing in the general adult population of Germany: can higher gaming time of males be explained by gender specific genre preferences? Comput. Hum. Behav. 55, 729-735. doi: 10.1016/j.chb.2015.10.016

Richardson, A. E., Powers, M. E., and Bousquet, L. G. (2011). Video game experience predicts virtual, but not real navigation performance. Comput. Hum. Behav. 27, 552-560. doi: 10.1016/j.chb.2010.10.003

Riva, G., and Waterworth, J. A. (2003). Presence and the self: a cognitive neuroscience approach. Presence-Connect 3.

Riva, P. G. (2006). "Being-in-the-world-with: presence meets social and cognitive neuroscience," in From Communication to Presence: Cognition, Emotions and Culture Towards the Ultimate Communicative Experience, eds P. G. Riva, P. M. T. Anguera, P. B. K. Wiederhold, and P. F. Mantovani (Amsterdam: IOS Press). Available online at: http://cogprints.org/5966/

Robillard, G., Bouchard, S., Renaud, P., and Cournoyer, L.-G. (2002). Validation canadienne-française de deux mesures importantes en réalité virtuelle: L'Immersive Tendencies Questionnaire et le Presence Questionnaire. Poster presented at the 25ième congrès de la Société Québécoise pour la Recherche en Psychologie (SQRP).

Rosa, P. J., Morais, D., Gamito, P., Oliveira, J., and Saraiva, T. (2016). The immersive virtual reality experience: a typology of users revealed through multiple correspondence analysis combined with cluster analysis technique. Cyberpsychol. Behav. Soc. Netw. 19, 209-216. doi: 10.1089/cyber. 2015.0130

Rowlands, M. J. (2010). The New Science of the Mind: From Extended Mind to Embodied Phenomenology. Cambridge, MA: MIT Press.

Saputra, R., Iqbal, B. M., and Komarudin. (2017). "Stress emotion evaluation in Multiplayer Online Battle Arena (MOBA) video game related to gaming rules using Electroencephalogram (EEG)," in Proceedings of the 2017 4th International Conference on Biomedical and Bioinformatics Engineering, (New York, NY: Association for Computing Machinery), 74-77.

Saucier, D. M., Green, S. M., Leason, J., MacFadden, A., Bell, S., and Elias, L. J. (2002). Are sex differences in navigation caused by sexually dimorphic strategies or by differences in the ability to use the strategies? Behav. Neurosci. 116, 403-410. doi: 10.1037//0735-7044.116.3.403

Schubert, T., Friedmann, F., and Regenbrecht, H. (2001). The experience of presence: factor analytic insights. Presence 10, 266-281. doi: 10.1162/105474601300343603

Schultze, U. (2010). Embodiment and presence in virtual worlds: a review. J. Inform. Tech. 25, 434-449. doi: 10.1057/jit.2010.25

Schwind, V., Knierim, P., Haas, N., and Henze, N. (2019). "Using presence questionnaires in virtual reality," in Proceedings of the 2019 CHI Conference on Human Factors in Computing Systems (New York, NY: Association for Computing Machinery), 1-12.

Scozzari, S., and Gamberini, L. (2011). Virtual reality as a tool for cognitive behavioral therapy: a review," in Advanced Computational Intelligence Paradigms in Healthcare 6. Virtual Reality in Psychotherapy, Rehabilitation, and Assessment, eds S. Brahnam, and L. C. Jain (Berlin: Springer), 63-108.

Shafer, D.-M., Carbonara, C.-P., and Kropi, M.-F. (2017). Modern virtual reality technology: cybersickness, sense of presence, and gender. Med. Psychol. Rev. 11.

Sheridan, T. B. (1992). Musings on telepresence and virtual presence. Presence 1, 120-126. doi: 10.1162/pres.1992.1.1.120

Silverman, I., and Eals, M. (1992). "Sex differences in spatial abilities: evolutionary theory and data," in The Adapted Mind: Evolutionary Psychology and The Generation of Culture, (New York, NY: Oxford University Press), 533-549.

Slater, M. (2004). How colorful was your day? Why questionnaires cannot assess presence in virtual environments. Presence 13, 484-493. doi: $10.1162 / 1054746041944849$

Slater, M. (2018). Immersion and the illusion of presence in virtual reality. Br. J. Psychol. 109, 431-433. doi: 10.1111/bjop.12305

Slater, M., Linakis, V., Usoh, M., and Kooper, R. (1996). “Immersion, presence and performance in virtual environments: an experiment with tri-dimensional chess," in Proceedings of the ACM Symposium on Virtual Reality Software and Technology (New York, NY: VRST), 163-172.

Slater, M., and Usoh, M. (1994). "Body centred interaction in immersive virtual environments," in Artificial Life and Virtual Reality, eds N. Magnenat Thalmann, and D. Thalmann (New York, NY: John Wiley and Sons), 125-148.

Slater, M., Usoh, M., and Steed, A. (1994). Depth of presence in virtual environments. Presence 3, 130-144. doi: 10.1162/pres.1994.3.2.130

Slater, M., and Wilbur, S. (1997). A Framework for Immersive Virtual Environments (FIVE): speculations on the role of presence in virtual environments. Presence 6, 603-616. doi: 10.1162/pres.1997. 6.6 .603

Smith, S. M., and Vela, E. (2001). Environmental context-dependent memory: a review and meta-analysis. Psychon. Bull. Rev. 8, 203-220. doi: 10.3758/bf03196157

Stanney, K. M., Fidopiastis, C., and Foster, L. (2020). Virtual reality is sexist: but it does not have to be. Front. Robot. AI 7:4. doi: 10.3389/frobt.2020.00004

Stanney, K. M., Kingdon, K. S., Graeber, D., and Kennedy, R. S. (2002). Human performance in immersive virtual environments: effects of exposure duration, user control, and scene complexity. Hum. Perform. 15, 339-366. doi: 10.1207/S15327043HUP1504_03

Stevens, J. A., and Kincaid, J. P. (2015). The relationship between presence and performance in virtual simulation training. Open J. Model. Simul. 03, 41-48. doi: 10.4236/ojmsi.2015.32005

Stoffregen, T. A., and Smart, L. J. (1998). Postural instability precedes motion sickness. Brain Res. Bull. 47, 437-448. doi: 10.1016/S0361-9230(98)00102-6 
Sullivan, J. V. (2018). Learning and embodied cognition: a review and proposal. Psychol. Learn. Teach. 17, 128-143. doi: 10.1177/1475725717752550

Tarampi, M. R., Heydari, N., and Hegarty, M. (2016). A tale of two types of perspective taking: sex differences in spatial ability. Psychol. Sci. 27, 1507-1516. doi: $10.1177 / 0956797616667459$

Thompson, E. (2007). Mind in Life. Cambridge, MA: Harvard University Press.

Treisman, M. (1977). Motion sickness: an evolutionary hypothesis. Science 197, 493-495.

Waller, D., Hunt, E., and Knapp, D. (1998). the transfer of spatial knowledge in virtual environment training. Presence 7, 129-143. doi: 10.1162/105474698565631

Weech, S., Kenny, S., and Barnett-Cowan, M. (2019). Presence and cybersickness in virtual reality are negatively related: a review. Front. Psychol. 10:158. doi: $10.3389 /$ fpsyg.2019.00158

Weech, S., Kenny, S., Lenizky, M., and Barnett-Cowan, M. (2020). Narrative and gaming experience interact to affect presence and cybersickness in virtual reality. Int. J. Hum. Comput. Stud. 138:102398. doi: 10.1016/j.ijhcs.2020. 102398

Welch, R. B. (1999). How can we determine if the sense of presence affects task performance? Presence 8, 574-577. doi: 10.1162/105474699566387

Welch, R. B., Blackmon, T. T., Liu, A., Mellers, B. A., and Stark, L. W. (1996). The effects of pictorial realism, delay of visual feedback, and observer interactivity on the subjective sense of presence. Presence 5, 263-273. doi: 10.1162/pres.1996.5.3.263

Wirth, W., Hartmann, T., Boecking, S., Vorderer, P. A., Klimmt, C., Schramm, H., et al. (2007). A process model of the formation of spatial presence experiences. Media Psychol. 9, 493-525. doi: 10.1080/15213260701 283079

Witkin, H., Lewis, H., Hertman, M., Goodenough, D., and Karp, S. (1962). Psychological Differentiation. Oxford: Wiley.
Witmer, B. G., and Singer, M. F. (1994). Measuring Presence in Virtual Environments. United States Army Research Institute for the Behavioral Sciences. Available online at: https://apps.dtic.mil/docs/citations/ADA286183.

World Medical Association. (2013). Declaration of Helsinki: ethical principles for medical research involving human subjects. JAMA 310, 2191-2194. doi: 10.1001/jama.2013.281053

Yee, N. (2017). Beyond 50/50: Breaking Down The Percentage of Female Gamers By Genre. Quantic Foundry. Available online at: https:/quanticfoundry.com/2017/ 01/19/female-gamers-by-genre/.

Youngblut, C., and Huie, O. (2003). "The relationship between presence and performance in virtual environments: results of a VERTS study," in Proceedings of the IEEE Virtual Reality (Los Angeles, CA: IEEE), 277-278.

Zahorik, P., and Jenison, R. L. (1998). Presence as being-in-the-world. Presence 7, 78-89. doi: 10.1162/105474698565541

Zhou, Y., Wen, D., Lu, H., Yao, W., Liu, Y., Qian, W., et al. (2020). The current research of spatial cognitive evaluation and training with brain-computer interface and virtual reality. Front. Neurosci. 13:143. doi: $10.3389 /$ fnins. 2019.0143

Conflict of Interest: The authors declare that the research was conducted in the absence of any commercial or financial relationships that could be construed as a potential conflict of interest.

Copyright $\odot 2020$ Maneuvrier, Decker, Ceyte, Fleury and Renaud. This is an openaccess article distributed under the terms of the Creative Commons Attribution License (CC BY). The use, distribution or reproduction in other forums is permitted, provided the original author(s) and the copyright owner(s) are credited and that the original publication in this journal is cited, in accordance with accepted academic practice. No use, distribution or reproduction is permitted which does not comply with these terms. 